\title{
The Costs and Benefits of Writing, Talking, and Thinking About Life's Triumphs and Defeats
}

\author{
Sonja Lyubomirsky, Lorie Sousa, and Rene Dickerhoof \\ University of California, Riverside
}

\begin{abstract}
Three studies considered the consequences of writing, talking, and thinking about significant events. In Studies 1 and 2, students wrote, talked into a tape recorder, or thought privately about their worst $(N=$ 96) or happiest experience $(N=111)$ for 15 min each during 3 consecutive days. In Study $3(N=112)$, students wrote or thought about their happiest day; half systematically analyzed, and half repetitively replayed this day. Well-being and health measures were administered before each study's manipulation and 4 weeks after. As predicted, in Study 1, participants who processed a negative experience through writing or talking reported improved life satisfaction and enhanced mental and physical health relative to those who thought about it. The reverse effect for life satisfaction was observed in Study 2, which focused on positive experiences. Study 3 examined possible mechanisms underlying these effects. Students who wrote about their happiest moments-especially when analyzing them-experienced reduced well-being and physical health relative to those who replayed these moments. Results are discussed in light of current understanding of the effects of processing life events.
\end{abstract}

Keywords: positive experience, health, well-being, rumination, expressive writing

Significant life events can be processed in a number of ways. Some people write about their experiences in a journal; others talk about their concerns with friends or family; still others prefer to think about their situation privately or not do anything at all. Whether the significant experience is negative (e.g., an injury, death of a friend, loss of salary, divorce) or positive (e.g., marriage, birth of a child, promotion, graduation), the way that one responds to the experience may differentially affect the outcome for one's well-being and health. The primary question motivating the present research is, Which ways of processing negative and positive experiences are most beneficial and why?

Experiencing unpleasant or traumatic circumstances can affect an individual's sense of meaning and order in the world. Consequently, seeking to restore meaning and order is a common and adaptive way of coping with negative events. However, it appears that not all methods of seeking meaning are created equal. Previous research suggests that the ways in which people process their thoughts under adverse circumstances-namely, whether they engage in thinking privately versus writing or talking-can influence

Sonja Lyubomirsky, Lorie Sousa, and Rene Dickerhoof, Department of Psychology, University of California, Riverside.

Lorie Sousa is now at Sanford Systems, Wildomar, California.

This research was supported in part by an intramural grant from the Academic Senate of the University of California, Riverside, and a dissertation grant from the Graduate Division. We thank Sanford Systems for graciously hosting our study Web site. We are also grateful to Katie Frieboes, Antoinette Lee, James Chin, Andrea Gutierrez, Mia Lyon, Meaghan Burroughs, and Wayne Roemhil for assisting with data collection; to Robin DiMatteo, Sunil Erevelles, Joanne Frattaroli, and Charlotte Castro-Markey for valuable comments on this research; and to Bob Rosenthal and Dan Ozer for their statistical advice.

Correspondence concerning this article should be addressed to Sonja Lyubomirsky, Department of Psychology, University of California, Riverside, CA 92521. E-mail: sonja.lyubomirsky@ucr.edu whether the outcome for mental and physical health is favorable or unfavorable (Greenberg, Wortman, \& Stone, 1996; Lyubomirsky \& Nolen-Hoeksema, 1995; Murray \& Segal, 1994; Pennebaker \& Seagal, 1999).

In contrast to the literature on negative life events, work on processing positive experiences is relatively sparse. Research has tended to focus on negative life circumstances and the ways in which they are processed and managed (Seligman \& Csikszentmihalyi, 2000). Demonstrating the utility of processing positive life experiences in specific ways-for example, by journaling, talking, or thinking privately about them-would represent a much needed advance in research.

\section{THEORY AND RESEARCH ON NEGATIVE EXPERIENCES}

\section{Effects of Writing and Talking}

A large and growing literature supports the premise that writing about past traumatic experiences has beneficial consequences for well-being and health (for reviews, see Frattaroli, in press; Smyth, 1998), such as less distress, negative affect (NA), and depression over time (Dominguez et al., 1995; Greenberg \& Stone, 1992; Murray \& Segal, 1994). Furthermore, those who simply talk about a traumatic experience into a tape recorder (as though they are talking to a friend) are just as likely to benefit as those who write about the experience (Murray \& Segal, 1994). Discussing a traumatic event during brief psychotherapeutic sessions has also been found to increase well-being (Donnelly \& Murray, 1991). Finally, the literature on social support is relevant, as levels of social contact have been found to be related to better mental and physical health (DeLongis, Folkman, \& Lazarus, 1988; Holahan \& Moos, 1985; Vinokur, Schul, \& Caplan, 1987; see also Gable, Reis, Impett, \& Asher, 2004). 
In a meta-analysis of 146 studies, Frattaroli (in press) found a positive and significant benefit of both writing and talking about negative life events. Thus, on the basis of existing research, we suspect that writing and talking will have similar outcomes for people's well-being and health. By contrast, thinking about an unhappy life event is expected to produce relatively less favorable results.

\section{Effects of Thinking}

Contrary to studies on the effects of writing and talking, research overwhelmingly suggests that thinking about traumatic life events does not result in beneficial outcomes. The search for meaning and understanding that typically follows the experience of a traumatic event - although deemed necessary and beneficialunfortunately has the potential to degenerate into a series of repetitive, negative, and intrusive thoughts-namely, "rumination" (Hixon \& Swann, 1993; Nolen-Hoeksema, McBride, \& Larson, 1997; Nolen-Hoeksema \& Morrow, 1991). Numerous studies have documented that self-focused rumination produces a host of adverse outcomes, including prolonging dysphoric mood, enhancing negatively biased and pessimistic thoughts and memories, and interfering with problem solving, motivation, and concentration (for reviews, see Lyubomirsky \& Tkach, 2004; Nolen-Hoeksema, 2003).

In sum, thinking about traumatic or stressful life experiences can often be self-perpetuating and repetitive and can result in a host of negative consequences. Thus, in Study 1, we hypothesized that thinking, unlike writing and talking, would be associated with detrimental outcomes when processing negative experiences.

\section{Mechanisms Underlying the Different Outcomes of Writing, Talking, and Thinking}

Why might different ways of processing traumatic events result in such disparate outcomes? A review of the literature suggests that writing, talking, and thinking might result in differing levels of integration and synthesis. Thus, we can speculate about the ways in which writing and talking are distinct from thinking.

Writing and talking tend to involve organizing, integrating, and analyzing one's problems with a focus on solution generation or at least acceptance. The highly structured nature of language and syntax invites organization and analysis that occur in the process of creating a narrative, which often leads to searching for meaning, enhanced understanding, and identity formation (Singer, 2004; Smyth, True, \& Souto, 2001). Once the structure and meaning of an experience is understood, the individual gains a sense of resolution and control and is better able to manage his or her emotions about the experience (Pennebaker \& Graybeal, 2001). Furthermore, writing or talking about traumatic experiences helps a person label his or her emotions, which may allow him or her to understand them and to let go (Esterling, L'Abate, Murray, \& Pennebaker, 1999; Swinkels \& Giuliano, 1995). Other studies have shown that improvements in health and other outcomes are associated with the use of causal and insight words (presumably related to integration) during the writing process (Esterling et al., 1999; Pennebaker, Mayne, \& Francis, 1997); with organization, acceptance, and the formation of a narrative (Pennebaker \& Seagal, 1999); and with integration of memories in self-understanding (Blagov \& Singer, 2004).
By contrast, thinking is inherently disorganized and even chaotic and includes not only words but also images, intense emotions, and memories. Indeed, the disorganized and unintegrated nature of traumatic memories (Foa \& Riggs, 1993; van der Kolk \& van der Hart, 1991) may keep them cycling in one's mind until they are organized, integrated, and recorded. In addition, as discussed above, private thought appears to be inclined to degrade into repetitive dwelling. Perhaps writing and talking provide a channel leading to the release of painful experiences, whereas thinking provides a channel leading to the reexperience and maintenance of painful experiences in memory (cf. Martin \& Tesser, 1989).

Of course, not all private thought results in rumination and dwelling. A distinction can be made between the relatively less adaptive types of repetitive thought, which include rumination and intrusive thinking, and the relatively more adaptive types, which include working through (Horowitz, Field, \& Classen, 1993), reflection (Hixon \& Swann, 1993; Trapnell \& Campbell, 1999), and emotional processing (Stanton, Kirk, Cameron, \& DanoffBurg, 2000). A pattern emerges, such that the less adaptive types of thought are typically repetitive, less controllable, and associated with negative mood, whereas the more adaptive types are relatively more deliberate, systematic, searching, and analytical in nature, akin to problem solving and curiosity (see Segerstrom, Stanton, Alden, \& Shortridge, 2003).

Finally, writing and talking involve recording or documenting one's thoughts externally-either on a piece of paper or into a tape recorder or other source-whereas thinking does not. Perhaps people tend to rehearse, reexperience, and elaborate significant events to record them in their memories. Writing or speaking about one's thoughts out loud may be a means to unburden oneself by chronicling them externally, thus allowing oneself to move past one's troubles.

\section{THEORY AND RESEARCH ON POSITIVE EXPERIENCES}

Unfortunately, the processing of positive experiences has not received comparable attention from researchers. Researchers may assume that processing positive events is unimportant because it does not involve suffering and its alleviation. However, one could argue that learning what processes maintain and stimulate positive emotions, which undoubtedly accompany the reexperience and processing of happy events, does help advance understanding of how to relieve suffering. For example, researchers have suggested that the cultivation of positive emotions may stimulate well-being, health, and general functioning (Fredrickson, 2001; Salovey, Rothman, Detweiler, \& Steward, 2000). According to Fredrickson's (2001) broaden-and-build theory, positive emotions broaden one's cognitions and actions and foster growth and coping skills. As a result, positive emotions build durable physical, cognitive, and social resources-for example, physical play, intellectual exploration, and sharing with others (e.g., Fredrickson \& Joiner, 2002; Fredrickson, Tugade, Waugh, \& Larkin, 2003). These resources can promote multiple successful outcomes-in the domains of social relationships, work, and physical and mental health (see Lyubomirsky, King, \& Diener, 2005).

Positive emotions may also serve as a resource in the prevention and treatment of psychological problems stemming from negative 
emotions, such as anxiety, depression, and stress-related health problems (Fredrickson, 2000). For example, the emotions of joy and contentment have been found to have an undoing effect on negative emotions (Fredrickson \& Levenson, 1998; Fredrickson, Mancuso, Branigan, \& Tugade, 2000) and on physiological arousal (Hughes, Uhlmann, \& Pennebaker, 1994; Salovey et al., 2000). Indeed, writing about the positive (as opposed to negative) emotions associated with a traumatic experience is associated with lowered heart rate and skin conductance levels (Hughes et al., 1994). Inductions of positive affect (PA) have also been found to enhance good health and immune function, including a return to baseline for levels of negative emotional arousal and cardiovascular activation (Fredrickson \& Levenson, 1998), the release of antibodies responsible for fighting off the cold virus (Stone, Cox, Valdimarsdottir, Jandorf, \& Neale, 1987), and fewer illnesses and physician visits (Goldman, Kraemer, \& Salovey, 1996).

Another path by which PA and positive experiences may be associated with health is by providing the psychological resilience needed to face health threats. Salovey et al. (2000) suggested that individuals who experience positive emotions may be more likely to use health-promoting behaviors and to respond to health threats. For example, studies have shown that individuals who experience more PA may be better equipped to manage and cope with health issues when they arise (e.g., Aspinwall \& Brunhart, 1996; Irving, Snyder, \& Crowson, 1998).

\section{Comparing Writing, Talking, and Thinking}

In sum, the research described above suggests that by helping an individual to cultivate physical, intellectual, and social resources, the experience and maintenance of positive emotions can be instrumental in promoting well-being, boosting health, and aiding coping with life's disappointments and failures. Thus, it would be important to determine which particular ways of responding to happy life experiences best maintain PA. Because writing, talking, and thinking about negative life events appear to be associated with different outcomes, we suggest that processing positive life events by using these three methods may also trigger and maintain different levels of PA and thus be associated with differential benefits to happiness and health.

Recall that writing and talking tend to invoke organization, integration, analysis, and a methodical approach. This quality appears to be beneficial in the context of NA (i.e., when processing negative events), yet it might interfere with the experience of PA (i.e., when processing positive events). For example, processing a joy or triumph analytically, step by step (as one may do when writing or talking about it), may lead to the questioning of one's good fortune (e.g., "Maybe I don't deserve this"), to consideration of the possible counterfactuals (e.g., "What if I had not been at the right place at the right time?"), or to the deliberation of possible down sides (e.g., "My friends will be jealous now and might snub me"). Consequently, systematic analysis of positive events through writing or talking could be detrimental, as it may serve to break such events down into their constituent parts, to reduce the pleasure associated with them, and even to evoke negative emotions, such as guilt or worry.

Theory and research by Wilson and his colleagues bolster our arguments. These researchers have shown that uncertainty following a positive event prolongs the pleasure it yields, whereas certainty reduces pleasure (Wilson, Centerbar, Kermer, \& Gilbert,
2005). Their findings corroborate our prediction that systematic analysis of positive events is counterproductive. According to Wilson and Gilbert (2003), analyzing a positive event and trying to make sense of it serves to "ordinize" it. That is, "meaning making" through systematic analysis removes any uncertainty or mystery surrounding positive experiences, transforming them from something surprising, thrilling, and extraordinary into something mundane, ordinary, and less emotionally intense.

In contrast to the arguments regarding analysis, we submit that thinking repetitively (e.g., ruminating) about positive events could be beneficial for the individual. Repetitive replaying and rehearsal of a particular experience tends to maintain its surrounding emotions-a process that is undesirable when the experience is negative but valuable when it is positive. Thus, thinking about a happy moment or wonderful experience-passively, repetitively, without analysis - may help sustain PA because it allows the individual to savor, rehearse, and reexperience it.

\section{Relevant Prior Research}

Unfortunately, to our knowledge, no studies have directly compared different ways of responding to happy experiences, and only a handful of investigations to date, reviewed below, have examined people's reactions to such experiences.

Research on "capitalization" suggests that, unlike negative events, positive events can provide opportunities to capitalize on good fortune. For example, expressive responses to positive life events (e.g., telling others or throwing a party) have been associated with PA above and beyond the valence of the positive events themselves (Langston, 1994). Communicating positive events to others has also been related to increased PA and well-being, especially when this communication is responded to in active and constructive ways (e.g., with enthusiasm rather than criticism; Gable et al., 2004). However, capitalizing responses to happy experiences cannot be equated with either talking or writing per se, as they can include a diverse set of behaviors and need not involve a narrative or analysis of the event in question. Furthermore, the effects of capitalization on well-being are likely due in part to the benefits of communication and social support.

Several studies by King and her colleagues have investigated whether writing about positive topics promotes successful selfregulation and, consequently, produces benefits for health and well-being. The results of one study supported the hypothesis that writing about the positive aspects of a traumatic life event promotes self-regulatory processes that, in turn, lead to some of the same health benefits found when writing about trauma alone (King \& Miner, 2000). Two other studies, which addressed positive events more directly, obtained evidence of health benefits for participants who wrote about their best possible future selves (King, 2001) or about peak experiences (Burton \& King, 2004). These findings appear to support our intuitions that replaying and rehearsing happy moments is beneficial, as King's instructions directed her participants to write in a manner that replays rather than analyzes the experience in question-that is, "write about the experience in as much detail as possible trying to include the feelings, thoughts, and emotions that were present at the time ... try your best to reexperience the emotions involved" (Burton \& King, 2004, p. 155).

Researchers have also found benefits for well-being through a writing exercise - specifically, the practice of writing down on a 
daily or weekly basis the five things for which one is grateful or thankful (Emmons \& McCullough, 2003; Lyubomirsky, Sheldon, $\&$ Schkade, 2005). However, because the writing involves a simple list (e.g., "my mom, my new girlfriend, last week's A in math"), it cannot be equated with the more complex writing examined in the present studies.

Finally, work on "savoring" has shown that people's perceptions of their ability to savor positive experiences-that is, relishing positive moments, anticipating future positive events, and reminiscing about pleasant past experiences-are robustly related to reports of greater well-being (Bryant, 1989, 2003). Furthermore, researchers have identified individual differences in the ways that people respond to positive experiences - that is, whether they tend to savor or dampen their PA (Wood, Heimpel, \& Michela, 2003). These findings suggest that savoring is a valuable and beneficial exercise, which, we submit, comes more easily when an individual replays a positive event than when he or she systematically analyzes it.

In summary, researchers are only beginning to explore the ways that people process and respond to happy life events. The aim of our Studies 2 and 3 was to compare directly the impact of different modes of processing of positive experiences.

\section{PRESENT RESEARCH}

\section{Study 1}

Previous research suggests that processing traumatic experiences by writing or talking about them results in beneficial outcomes. To our knowledge, no studies have compared writing and talking about a traumatic experience with thinking about it, although a separate literature on private thought suggests that the latter may be detrimental to functioning. To remedy this gap, our first study was aimed at determining which ways of processing traumatic experiences are most beneficial to students' well-being and health. Participants generated a traumatic or negative event and either wrote, talked aloud, or thought privately about that event for 15 min during each of 3 consecutive days. Our primary hypothesis for this study was that thinking about significant negative life experiences would be associated with less favorable outcomes 4 weeks later than would writing or talking about them.

\section{Study 2}

Our second and third studies focused on pleasant experiences. The procedure of Study 2 was identical to that of Study 1, except that students considered their happiest life event. We hypothesized that thinking about significant positive life experiences would be associated with more favorable outcomes, such as enhanced life satisfaction, than would writing or talking about them. This hypothesis, which was essentially the inverse of that for Study 1, was based on the assumption that the organized, analytical, and externalizing nature of writing and talking may be inherently incompatible with the maintenance of PA, resulting in unfavorable outcomes for these two groups.

\section{Study 3}

The aim of our third study was to manipulate directly the amount of systematic analysis or repetitive replaying during the exercise of writing or thinking about a positive life event. As described above, we anticipated that when it comes to the best experiences in life - an individual's joys and victories - it is repetitive replaying and rehearsal of the experience that is likely to maintain the positive emotions surrounding it and to enhance well-being generally. In contrast, step-by-step analysis of a positive event by breaking it down into its component parts is likely to diminish pleasure and well-being. Accordingly, the purpose of Study 3 was to explore an important possible mechanism (i.e., replay vs. analysis) that underlies the relationship between different modes of processing positive events and outcomes for positive emotions and health. To this end, participants were instructed to either write or think about one of their happiest days for 8 min each day for 3 consecutive days. Half were induced to systematically analyze their positive experience while writing or thinking, and half were induced to repetitively replay it.

Our primary hypothesis for this study was that thinking about positive experiences-especially when the thinking involves repetitive replaying and rehearsal-would be the most beneficial method of processing to a person's long-term PA, general wellbeing, and health. In contrast, writing about a happy life experience-particularly when the writing involves step-by-step analysis-was expected to be the most detrimental method. Accordingly, we predicted that writing while analyzing would be especially detrimental when compared with thinking while replaying.

\section{STUDY \\ Method \\ Participants}

Ninety-six students (70 female and 26 male) were recruited from the undergraduate psychology student participant pool at the University of California, Riverside. Three additional participants failed either to follow directions or to complete the entire study and were dropped from the analyses. Although data regarding ethnicity were not collected, the participant pool typically consists of approximately $40 \%$ Asians, $20 \%$ Latino(a)s, 20\% Caucasians, 10\% African Americans, and 10\% "other." Participants' ages ranged from 17 to 38 years $(M=19.88$ years, $S D=3.35$ years). Students were matched across conditions for gender. On the basis of their responses to a mass-administered questionnaire, those who scored above 16 on the Beck Depression Inventory (Beck, 1967) were excluded from participation in the study.

\section{Procedure}

Participants completed a packet of outcome measures administered during their introductory psychology class. From this initial mass administration, 36 students (who did not participate in any manipulation) were randomly selected to serve as the comparison group, and the remaining 60 were randomly assigned to one of the experimental groups-that is, writing, talking, or thinking. These three experimental groups were asked to sign up for 3 consecutive days of participation followed by an e-mail contact to take place 4 weeks subsequent to their $3 \mathrm{rd}$ day of initial participation. The experimental participants were tested individually. First, they were asked to read an information form that briefly described the tasks involved in the study and informed them of their rights as participants. Then they received a packet of outcome measures.

\section{Outcome Measures}

The following measures were administered to participants two times during the course of the study — at Time 1 (i.e., during the 1 st week of their 
psychology class for the comparison group and on their 1st day of participation for the three experimental groups) and at Time 2 (i.e., 4 weeks subsequent to administration of the Time 1 measures via an e-mail message for all groups).

\section{Demographics Questionnaire}

The first questionnaire requested information about each participant's date of birth, gender, e-mail address, and college major.

\section{Life Satisfaction}

The next measure administered was the Satisfaction With Life Scale (SWLS; Diener, Emmons, Larsen, \& Griffin, 1985), which assesses respondents' current satisfaction with their life in general. It consists of five questions (e.g., "In most ways my life is close to my ideal"), which are rated on 7-point Likert-type scales $(1=$ strongly disagree, 7 strongly agree; $\alpha \mathrm{s}=.88$ and .89 for Time 1 and Time 2, respectively). Validation studies have shown that the SWLS comprises a single factor and possesses high internal consistency $(\alpha=.87)$ and high test-retest reliability $(r=.82$; Diener et al., 1985).

\section{Transient Affect}

Participants then completed the Positive and Negative Affect Schedule (PANAS; Watson, Clark, \& Tellegen, 1988), which lists 20 adjectives. Ten adjectives reflect PA (e.g., proud, interested, alert), and 10 reflect NA (e.g., nervous, irritated, afraid). The instructions ask respondents to rate their current experience of each item (i.e., how they feel right now) by using 5 -point scales $(1=$ very slightly or not at all, $5=$ extremely $)$. Composites for PA and NA were created by averaging separately the scores of the adjectives denoting PA and those denoting NA $(\alpha=.70$ for Time 1 PA, $\alpha=.77$ for Time $1 \mathrm{NA}, \alpha=.91$ for Time $2 \mathrm{PA}$, and $\alpha=.90$ for Time 2 NA). In previous studies, the PANAS has been shown to have alphas ranging between .76 and .85 (Watson et al., 1988).

\section{Health Survey}

The Medical Outcomes Study Short-Form-20 Health Survey (Stewart, Hays, \& Ware, 1988) is an inventory intended to tap an individual's current general functioning and physical health (Time $1, \alpha=.70$; Time $2, \alpha=$ .86). The measure consists of six subscales, assessing health perceptions ( 5 items); mental health (5 items); pain (1 item); and physical (6 items), role (2 items), and social functioning (1 item).

The Health Perceptions subscale asks participants to rate their beliefs about their health (e.g., "I am as healthy as anybody I know"), by using 5 -point Likert-type scales $(1=$ definitely false, $5=$ definitely true $)$. The Mental Health subscale asks participants to rate their mental health status (e.g., "During the past month, how much of the time have you ... felt calm and peaceful?"; 1 = all of the time, $6=$ none of the time). The subscale measuring physical functioning requests that participants assess their physical ability to perform various physical tasks (e.g., "For how long [if at all] has your health limited you in the kinds or amounts of vigorous activities you can do, like lifting heavy objects, running, or participating in strenuous sports?"; 1 = not at all limited, 3 = limited for more than 3 months). The Role Functioning subscale consists of two questions (e.g., "Does your health keep you from working at a job, doing work around the house, or going to school?"; 1 = no, 2 = limited for 3 months or less, $3=$ yes, for more than 3 months). The Social Functioning subscale consists of the item, "How much of the time, during the past month, has your health limited your social activities (like visiting with friends or close relatives)?" $(1=$ all of the time, 6 = none of the time). Finally, the Pain subscale simply asks, "How much bodily pain have you had in the past 4 weeks?" $(1=$ none, 6 = very severe .
Following recommendations (Stewart et al., 1988), we standardized overall scores on the Health Survey by converting them to a 100-point scale. Overall, the Health Survey has good internal consistency, with alphas ranging between .81 and .87 . Consistent results have been found across age, gender, diagnostic, and educational groups. In addition, the convergent and discriminant validity of this scale has been evaluated by using multitrait analysis with good results (Stewart et al., 1988).

\section{Symptom Checklist}

The Symptom Checklist (Sherbourne, Allen, Kamberg, \& Wells, 1992) is intended to tap the experience of several common health problems (e.g., backaches, upset stomach, cold, allergies; $\alpha \mathrm{s}=.75$ and .74 at Time 1 and Time 2, respectively). Throughout the questionnaire, participants are asked to respond by indicating the frequency of their experience of each of 13 symptoms over the previous month $(1=$ never, $2=$ a few times in 4 weeks, $3=$ more than once a week, $4=3$ or 4 times a week, $5=$ nearly every day, and $6=$ everyday). This scale has been shown to have an alpha of .75 (Sherbourne et al., 1992).

\section{Experimental Manipulation}

\section{Preliminary Measures}

The following measures were administered to the three experimental groups on their 1st day of participation. The comparison group did not complete these questionnaires.

Worst Experience Questionnaire. This questionnaire asked participants to list the three worst or most traumatic experiences of their life and to rate how upsetting each experience was on a 10-point Likert-type scale $(1=$ not upsetting, $10=$ extremely upsetting $)$. Then, they were asked to highlight the one experience that was most upsetting to them.

Life Experience Questionnaire. Next, students completed a set of ratings regarding their very worst life experience. First, they were asked, "How recent was this experience?" (responses ranged from within the last week to 9 years ago to more than 9 years ago). The remaining items were rated on 10-point Likert-type scales: "How significant is this experience in your life?" ( 1 = not at all significant, 10 = very significant $)$;"How much time have you spent writing [talking aloud to others] [thinking (privately)] about this experience?" $(1=$ none, $10=a$ lot $)$. The final question asked, "Is this experience resolvable (meaning, do you think the experience can be easily resolved by you, or is it out of your control)?" ( 1 = not easily resolvable, $10=$ easily resolvable .

\section{Experimental Conditions}

Participants then experienced one of three manipulations. Participants in the writing group were asked to write about their experience. Those in the talking group were instructed to talk about their experience into an audiotape recorder. Finally, those in the thinking group were asked to think privately about their experience. Participants in these three experimental groups were exposed to the experimental conditions for exactly $15 \mathrm{~min}$ each day of their 3 days of participation.

Writing condition. In this condition, students were asked to write about their worst life experience on each day of participation. Participants were given several sheets of blank paper and then were read the following instructions, adapted from Pennebaker and Francis (1996):

For the next three days, I would like for you to write about your deepest thoughts and feelings regarding the significant life experience you highlighted on the questionnaire. In your writing, I'd like you to really let go and explore your deepest emotions and thoughts. You might tie your topic to your relationships with others including parents, significant others, friends, or relatives, to your past, your present, or your future, or to who you have been, who you would like to be, 
or who you are now. You may write about the same general issues or experiences on all days of writing or on different things each day... . Don't worry about using complete sentences or being logical. Just write whatever comes to your mind about this experience.

When the experimenter returned after $15 \mathrm{~min}$, the pages were collected and the final questionnaire of the session was administered.

Talking condition. In this condition, participants were asked to talk about their worst life experience on each day of participation. An audio recorder containing a 90-min tape labeled with the participant number and day of participation (Day 1, Day 2, or Day 3) was placed on the desk in front of the student. A small microphone was clipped to the participant's shirt. The instructions students heard were identical to those in the writing condition except that participants were told to think out loud as if they were talking to themselves. They were further told that, "although talking aloud may seem awkward at first, we find that most people get comfortable with it after a few minutes." When the 15 min were up, the experimenter reentered the room, turned off the audio recorder and microphone, and set the equipment aside. The experimenter then administered the final questionnaire of the session.

Thinking condition. In this condition, students were asked to think privately about their worst life experience on each day of participation. Thus, the participants' task involved no writing or talking. The instructions for this condition were identical to those provided in the writing condition except that participants were asked to think about their significant life experience rather than write about the experience. The experimenter reentered after $15 \mathrm{~min}$ and administered the final questionnaire of the session.

Comparison condition. Students in this group did not consider or process any life event. They were simply contacted via e-mail 4 weeks subsequent to the initial administration of the outcome measures and asked to complete them once again.

\section{Final Questionnaire}

After experimental participants completed 15 min of the manipulation each day, they were asked this final question, which we used as an approximate manipulation check: "How many of the last 15 minutes did you spend focusing on the task you were given?" (0-5 min, 5-10 min, 10-15 min, all $15 \mathrm{~min}$ ). Ratings for all 3 days were averaged to obtain a mean attention score.

\section{Follow-Up}

Four weeks following their participation, all participants were contacted via e-mail and asked to complete on the Web the final set of outcome measures, which were identical to the first set of measures. Finally, participants were sent a thorough debriefing e-mail detailing the purpose of the study and were asked to return an end consent form giving us permission to use their data.

\section{Results}

\section{Overview of Statistical Analyses}

In this study, levels of students' life satisfaction, transient affect, and health were assessed before and after they were induced to process their worst life experience-that is, at Time 1 (premanipulation) and at Time 2 (postmanipulation). The extent to which levels of these variables changed over time was examined by analyzing Time 2 data with Time 1 as a covariate (i.e., by using regressed change scores). ${ }^{1}$ Contrast analyses were then performed by using the adjusted scores.
On the basis of previous research, the writing and talking groups were expected to experience more favorable outcomes overall than the thinking group. To test this primary hypothesis, we performed planned contrasts (with Time 1 as a covariate) by comparing the thinking group with the writing and talking group, respectively, as well as with the two groups combined. ${ }^{2}$ Because these contrast analyses tested specific directional hypotheses, all reported $p$ values are one-tailed. Finally, we explored whether thinking about one's worst life event produces more adverse outcomes than not considering or processing a negative event at all, by comparing the thinking group with the comparison group (i.e., a sample from the general population of participants).

Examination of the demographic data revealed little variability in age and major (most students were psychology majors), and analyses of the primary dependent variables by gender, age, and major revealed no significant main effects or interactions. Thus, all analyses were collapsed across these variables. There were 20 participants in the writing group, 19 in the talking group, 21 in the thinking group, and 36 in the comparison group.

\section{Ratings of Respondents' Worst Experiences}

Post hoc analyses comparing each of the three experimental conditions were conducted to determine whether there were any initial significant differences among groups in their ratings of their most traumatic experiences. Death of a family member (e.g., mother, grandmother, uncle, brother), death of a pet, car accident, breaking up with a significant other, and domestic violence were some of the experiences mentioned. Overall, students rated their worst life event as extremely upsetting ( $M=9.01$ on a 10 -point scale) and very significant $(M=8.35$ on a 10-point scale). Participants' ratings of the recency of their self-generated negative life experiences revealed that, overall, this event occurred fairly recently — on average, between 1 and 3 years prior to the study. Participants also perceived their experience as being somewhat unresolvable $(M=4.24$ on a 10-point scale).

Analyses of ratings of how much time participants had spent writing, talking, or thinking about the negative experience before the study revealed that they spent very little time writing $(M=$ 3.50 on a 10-point scale), a moderate amount of time talking ( $M=$ 5.52 on a 10-point scale), and a lot of time thinking ( $M=7.13$ on a 10-point scale) about the experience.

No initial differences were found between the talking and thinking groups on any of these variables. However, despite random assignment, several significant differences emerged

\footnotetext{
${ }^{1}$ In all three studies, the results obtained by using covariance analyses (i.e., regressed change scores) were virtually identical to those obtained by using difference scores.

${ }^{2}$ The use of both pairwise and combined contrast codes in our three studies was deemed appropriate and desirable, after consultation with an expert on contrast analysis (R. Rosenthal, personal communication, May 14, 2004).
} 
Table 1

Marginal Means (Adjusted for Time 1) and Standard Errors for Processing Negative Events by Condition (Study 1)

\begin{tabular}{|c|c|c|c|c|c|c|c|c|}
\hline \multirow[b]{3}{*}{ Measure } & \multicolumn{8}{|c|}{ Condition } \\
\hline & \multicolumn{2}{|c|}{$\begin{array}{l}\text { Writing } \\
(n=20)\end{array}$} & \multicolumn{2}{|c|}{$\begin{array}{l}\text { Talking } \\
(n=19)\end{array}$} & \multicolumn{2}{|c|}{$\begin{array}{l}\text { Thinking } \\
(n=21)\end{array}$} & \multicolumn{2}{|c|}{$\begin{array}{c}\text { Comparison } \\
(n=36)\end{array}$} \\
\hline & $M$ & $S E$ & $M$ & $S E$ & $M$ & $S E$ & $M$ & $S E$ \\
\hline Satisfaction With Life & $4.81_{\mathrm{a}}$ & 0.19 & $4.76_{\mathrm{a}}$ & 0.20 & $4.25_{\mathrm{b}}$ & 0.19 & $4.67 \mathrm{a}$ & 0.15 \\
\hline Positive affect & $3.08_{\mathrm{a}}$ & 0.18 & $2.88_{\mathrm{a}}$ & 0.18 & $3.16_{\mathrm{a}}$ & 0.17 & $3.15_{\mathrm{a}}^{\mathrm{a}}$ & 0.13 \\
\hline Negative affect & $1.60_{\mathrm{a}}^{\mathrm{a}}$ & 0.15 & $1.59_{\mathrm{a}}^{\mathrm{a}}$ & 0.15 & $1.66_{\mathrm{a}}^{\mathrm{a}}$ & 0.15 & $1.60_{\mathrm{a}}^{\mathrm{a}}$ & 0.11 \\
\hline Overall health & $87.28_{\mathrm{a}}$ & 1.55 & $87.72_{\mathrm{a}}$ & 1.57 & $83.62_{\mathrm{b}}$ & 1.50 & $84.45_{\mathrm{a}, \mathrm{b}}^{\mathrm{a}}$ & 1.17 \\
\hline Physical Functioning & $97.23_{\mathrm{a}}$ & 1.87 & $97.17_{\mathrm{a}}$ & 1.91 & $97.72_{\mathrm{a}}$ & 1.82 & $96.54_{a}$ & 1.39 \\
\hline Pain & $87.55_{\mathrm{a}}^{\mathrm{a}}$ & 3.19 & $82.56_{a}^{a}$ & 3.30 & $80.74_{\mathrm{a}}^{a}$ & 3.11 & $77.35_{\mathrm{a}}^{\mathrm{a}}$ & 2.38 \\
\hline Role Functioning & $99.63_{\mathrm{a}}$ & 2.02 & $99.70_{\mathrm{a}}$ & 2.06 & $99.90_{\mathrm{a}}$ & 1.96 & $95.79 \mathrm{a}$ & 1.50 \\
\hline Social Functioning & $99.83_{\mathrm{a}}$ & 2.21 & $97.59_{\mathrm{a}, \mathrm{b}}$ & 2.27 & $94.17_{\mathrm{b}}$ & 2.15 & $96.80_{\mathrm{a}, \mathrm{b}}$ & 1.65 \\
\hline Mental Health & $75.98_{\mathrm{a}}^{\mathrm{a}}$ & 2.37 & $79.19 \mathrm{a}$ & 2.43 & $70.67_{\mathrm{b}}$ & 2.30 & $75.04_{\mathrm{a}, \mathrm{b}}^{\mathrm{a}}$ & 1.79 \\
\hline Health Perceptions & $67.70_{\mathrm{a}}$ & 4.03 & $67.89 \mathrm{a}$ & 4.12 & $62.11_{\mathrm{a}}$ & 3.92 & $65.32_{\mathrm{a}}$ & 2.99 \\
\hline Physical Symptoms & $1.31_{\mathrm{a}}$ & 0.08 & $1.36_{\mathrm{b}}$ & 0.09 & $1.54_{\mathrm{b}, \mathrm{c}}$ & 0.08 & $1.62_{\mathrm{c}}$ & 0.06 \\
\hline
\end{tabular}

Note. High scores indicate increasing functioning, except for negative affect and physical symptoms. Means that share subscripts are not significantly different from one another. The means for the thinking group are significantly different from those of the talking and writing groups (combined) for (a) satisfaction with life, (b) overall health, (c) social functioning, (d) mental health, and (e) physical symptoms.

between the writing group and the thinking group. ${ }^{3}$ Fortunately, despite these unexpected group differences, covariance analyses, using each of these variables (e.g., significance, recency) as separate covariates, revealed that these initial differences did not alter our results. Indeed, the results were stronger in the predicted direction with covariation.

\section{Manipulation Check}

Immediately after participants had completed each of the 3 days of the experimental manipulation, they were asked how much of the 15 min they spent processing their worst life event as instructed (i.e., by writing, talking, or thinking about it). Overall, students reported that they spent approximately $10-15 \min (M=2.60$ on a 4-point scale) focusing on their self-generated negative life event. It is interesting to note that analyses revealed significant group differences, $F(3,92)=17.88, p<.0001, \eta=.40$. That is, the writing group reported spending more time on the task $(M=$ 3.38 on a 4-point scale; $10-15 \mathrm{~min}$ ) than did the talking group $(M=2.44 ; 5-10 \mathrm{~min})$ or the thinking group $(M=2.02 ; 5-10 \mathrm{~min})$, possibly because writing was a relatively more compelling and engaging exercise and because hand writing an idea takes longer than thinking or saying it. Once again, however, despite differences among the experimental groups on this variable, covariance analyses with attention as a covariate revealed that these differences did not alter the results. In fact, group differences in our outcome measures were stronger in the predicted direction following covariation.

\section{Outcome Measures}

The estimated standardized marginal means (adjusted for Time 1) and standard errors for all our primary outcome measures are presented in Table 1.

\section{Life Satisfaction}

Participants who wrote or talked about their worst life experience were predicted to show improved life satisfaction, as assessed by the SWLS, relative to those who thought about it. Supporting this hypothesis, planned pairwise contrasts (with Time 1 as a covariate) revealed that participants in the thinking condition reported lower life satisfaction relative to those in the writing condition, $F(1,91)=4.26, p=.02, \eta=.22$, as well as relative to those in the talking condition, $F(1,91)=3.42, p=.03, \eta=.20$. Furthermore, planned contrasts indicated that the thinking group reported lower life satisfaction relative to both the talking and writing groups, $F(1,91)=5.21, p=.02, \eta=.22$, as well as relative to the comparison group, $F(1,91)=3.05, p=.04, \eta=$ .17 (Table 1).

\section{Transient Affect}

The thinking group was hypothesized to show reduced transient PA and increased NA relative to the other groups. However, contrary to predictions, no significant group differences were found for either PA or NA, as measured by the short-term PANAS (all $\left.F_{\mathrm{S}}<2, n s\right)$.

\section{Health Survey}

Overall health. Supporting our hypothesis, a planned contrast, with Time 1 as a covariate, indicated that students who simply

\footnotetext{
${ }^{3}$ Specifically, Tukey's honestly significant difference (HSD) post hoc analyses revealed that compared with the thinking group, the writing group reported their experiences to be significantly more upsetting $(M \mathrm{~s}=9.10$ vs. 8.71 on a 10 -point scale; $\mathrm{HSD}=0.74, p<.04)$, more significant $(M \mathrm{~s}=$ 9.10 vs. 7.67 on a 10 -point scale; $\mathrm{HSD}=1.43, p<.03$ ), and, finally, less recent $(M \mathrm{~s}=5.00$ vs. 6.83 -i.e., $<1$ year ago vs. $3-6$ years ago; HSD $=$ $-1.81, p<.003$ ). Additionally, the writing and thinking groups differed on how much time they reportedly spent writing $(M \mathrm{~s}=4.35$ vs. 2.52 on a 10 -point scale; $\mathrm{HSD}=1.82, p<.05)$ and thinking $(M \mathrm{~s}=8.30$ vs. 6.29 on a 10-point scale; HSD $=2.01, p<.01$ ) about their significant life experience. Finally, the writing and talking groups were found to differ on the recency of the experience $(M \mathrm{~s}=5.00$ vs. 7.05 -i.e., $<1$ year ago vs. $3-6$ years ago; HSD $=-2.05, p<.001)$. Gain scores were used in these analyses.
} 
thought about their negative life experience reported diminished overall health, as revealed in total Health Survey scores (Stewart et al., 1988), relative to those who wrote about it, $F(1,91)=3.51$, $p=.03, \eta=.20$, and those who talked aloud about it, $F(1,91)=$ $3.61, p=.03, \eta=.20$, as well as relative to both those who wrote and talked combined, $F(1,91)=4.81, p=.02, \eta=.22$ (see Table $1)$. However, a contrast of the thinking group and the comparison group did not reach statistical significance $(F<1)$.

Because the Health Survey comprises several subscales, further analyses could examine the role of various aspects of health. Analyses of two of the subscales-Mental Health and Social Functioning-revealed parallel findings to those for overall health.

Mental health. The thinking group reported significantly diminished mental health relative to the writing group, $F(1,91)=$ $3.38, p=.03, \eta=.19$, and the talking group, $F(1,91)=6.38, p<$ $.01, \eta=.26$, as well as relative to both groups combined, $F(1$, $91)=5.89, p=.01, \eta=.24$. Thinkers did not differ significantly, however, from those in our comparison group $\left(F_{\mathrm{s}}<3\right)$.

Social functioning. The thinking group reported reduced social functioning relative to the writing and talking groups combined, $F(1,91)=3.11, p=.04, \eta=.17$, as well as to the writing group only, $F(1,91)=3.78, p=.03, \eta=.20$. However, the thinking group did not differ significantly from the talking group $(F<2)$ or the comparison group $(F<1)$ on this variable.

\section{Physical Symptoms}

Analyses of Symptom Checklist (Sherbourne et al., 1992) scores (i.e., frequency of backaches, colds) corroborated in part the findings for overall physical health. Students who thought privately about their worst experience reported significantly more physical health symptoms than those who wrote or talked about it (combined), $F(1,91)=4.43, p=.02, \eta=.22$, as well as to those who wrote about it (individually), $F(1,91)=4.08, p=.02, \eta=.20$, but not compared with those who talked about it $(F<3)$ or did not consider an event at all $(F<1$; see Table 1$)$.

\section{Discussion}

Our findings generally supported our predictions. Overall, participants who were instructed to write or talk into a tape recorder about their very worst life experience for $15 \mathrm{~min}$ on each of 3 consecutive days reported improved well-being and health relative to participants instructed to think privately to themselves. When assessed 4 weeks subsequent to their initial participation, students who wrote or talked reported increased life satisfaction, enhanced mental health, improved overall health, improved social functioning, and fewer physical health symptoms relative to students who thought about their negative experience. In addition, students who thought privately about their unpleasant life event reported diminished life satisfaction relative to no-treatment controls as well as a (nonsignificant) trend toward inferior mental health and greater physical symptoms. It is worth noting, however, that the expected pattern of results with respect to physical health could be a reflection of a general positivity bias-that is, a happy, satisfied person is likely to rate his or her health and general functioning more positively. Future research could address this issue by relying on relatively more objective health reports from doctors and close others.
Contrary to expectations, the experimental groups did not differ in their experience of short-term PA and NA 4 weeks after the induction. In retrospect, this finding should not be unexpected, as affect is a state variable and, as such, is transient in nature. It is possible that affect is too transitory to expect an effect that endures 4 weeks after the induction. Further research using a broader range of instruments to measure affect may be needed to test this conjecture. To this end, a long-term assessment of affect was used in our last study (Study 3).

Unlike the consequences of managing negative experiences, the effects of processing positive life experiences in different ways have received little attention in the literature and remain something of a mystery. The goal of Study 2 was to investigate this issue.

\section{STUDY 2 \\ Method \\ Participants}

One hundred eleven participants ( 82 female and 29 male) were recruited from the undergraduate psychology student participant pool at the University of California, Riverside. Again, the participant pool is typically composed of roughly $40 \%$ Asians, 20\% Latino(a)s, 20\% Caucasians, 10\% African Americans, and 10\% "other." Participants ranged in age from 17 to 38 years $(M=19.43$ years, $S D=2.59$ years $)$ and, as in Study 1 , were matched across conditions for gender.

\section{Procedure and Materials}

Our second study aimed to explore the relative costs and benefits of writing, talking, and thinking about positive experiences-namely, the "best" experience of one's life. To this end, as in Study 1, participants were exposed to one of the three experimental inductions-writing, talking, or thinking about the significant life experience. The design was identical to that of Study 1, except for the point at which all participants, except for those in the comparison group, were asked to generate a significant life experience. In Study 2, experimental participants were asked the following question: "Please list the three (3) BEST or HAPPIEST experiences of your life." Next, they were asked to rate how joyful or happy each experience was on a 10-point Likert-type scale $(1=$ not happy, $10=$ extremely happy). Finally, they were instructed to highlight the one experience that was the most joyful or happy for them.

Cronbach's alphas for each of the primary outcome variables (Time 1 and Time 2, respectively) were as follows: $\alpha \mathrm{s}=.74$ and .93 for transient $\mathrm{PA} ; \alpha \mathrm{s}=.82$ and .86 for transient NA; $\alpha \mathrm{s}=.88$ and .91 for the Satisfaction With Life Scale; $\alpha \mathrm{s}=.74$ and .81 for the Health Survey; and $\alpha \mathrm{s}=.78$ and .86 for the Symptom Checklist.

\section{Results}

\section{Overview of Statistical Analyses}

As in Study 1, levels of participants' life satisfaction, transient affect, and health were assessed before (Time 1) and after (Time 2) they processed their happiest life experience. Again, the extent to which levels of these variables changed over time was determined by analyzing Time 2 data with Time 1 as a covariate (i.e., by using regressed change scores). Finally, the set of planned contrasts conducted to test our primary hypothesis was identical to that in Study 1.

Once again, analyses of all the primary outcome variables by gender and age revealed no significant main effects or interactions. 
Thus, presentation of the results collapsed across these variables. There were 36 participants in the comparison group (also used in Study 1), 24 in the writing group, 25 in the talking group, and 26 in the thinking group.

\section{Ratings of Respondents' Best Experiences}

As in Study 1, post hoc analyses comparing each of the three experimental conditions were conducted to ascertain any initial significant group differences on participants' ratings of their happiest life experiences. Gaining admission to the college of their choice, meeting their significant other, receiving a new car from their parents, becoming engaged, experiencing the birth of a sibling, going to a concert with friends, and graduating from high school were some of the experiences mentioned by participants. Overall, students rated their best life event as extremely happy ( $M=9.81$ on a 10 -point scale), very significant $(M=9.09$ on a 10-point scale), and as occurring between 6 months and 1 year previous to their participation in the study. Students also rated their self-generated positive event as somewhat within their own control ( $M=6.51$ on a 10 -point scale).

Furthermore, analyses revealed that participants spent a moderate amount of time writing ( $M=5.57$ on a 10-point scale), a lot of time talking ( $M=7.57$ on a 10-point scale), and a lot of time thinking ( $M=8.09$ on a 10 -point scale) about their positive experience prior to the study.

Finally, Tukey's HSD post hoc analyses revealed no significant differences among the three experimental groups on ratings of the happiness, significance, resolvability-controllability, and recency of their most pleasant life experience as well as on how much time they had spent writing, talking, and thinking about this experience before the study.

\section{Manipulation Check}

Analyses of how much time students spent focusing on the task during the study (i.e., writing, talking, or thinking about their happiest life event) showed significant group differences, $F(3$,
$107)=9.89, p<.001, \eta=.29$. As in Study 1 , the writing group reported spending the most time on the task on average $(M=3.17$ on a 4-point scale; $10-15 \mathrm{~min}$ ), followed by the talking group $(M=2.51 ; 5-10 \mathrm{~min})$ and the thinking group $(M=2.21 ; 5-10$ min), respectively.

Covariance analyses were conducted on all the primary outcome variables by using attention as a covariate. Despite significant group differences on this variable, these analyses revealed that the attention differences did not alter the critical results.

\section{Outcome Measures}

\section{Life Satisfaction}

According to our primary hypothesis, participants who thought about their happiest experience were expected to report enhanced life satisfaction 4 weeks later relative to those who wrote or talked about it. Planned pairwise comparisons revealed that the thinking group reported improved life satisfaction relative to the writing group, $F(1,107)=2.26, p=.07, \eta=.14$, and relative to the talking group, $F(1,107)=7.02, p<.01, \eta=.25$, as well relative to the writing and talking groups combined, $F(1,107)=5.79, p=$ $.009, \eta=.23$. Indeed, this pattern of results, shown in Table 2, is even more notable when compared with that found for the same variable in Study 1, in which students processed negative life events (shown in Table 1). Students in the thinking group, however, did not differ significantly from those in the comparison group $(F<2)$.

\section{Transient Affect and Health}

As evident from Table 2, our primary hypothesis was not supported for either transient PA (both $F_{\mathrm{S}}<2$ ), transient NA (both $F_{\mathrm{s}}<1$ ), overall and subscale Health Survey scores (all $F_{\mathrm{s}}<2$ ), or Symptom Checklist scores (both $F_{\mathrm{s}}<1$ ).

\section{Discussion}

Our hypothesis followed from the argument that writing and talking may promote a type of analysis incompatible with positive

Table 2

Marginal Means (Adjusted for Time 1) and Standard Errors for Processing Positive Events by Condition (Study 2)

\begin{tabular}{|c|c|c|c|c|c|c|c|c|}
\hline \multirow[b]{3}{*}{ Measure } & \multicolumn{8}{|c|}{ Condition } \\
\hline & \multicolumn{2}{|c|}{$\begin{array}{c}\text { Writing } \\
(n=24)\end{array}$} & \multicolumn{2}{|c|}{$\begin{array}{c}\text { Talking } \\
(n=25)\end{array}$} & \multicolumn{2}{|c|}{$\begin{array}{l}\text { Thinking } \\
(n=26)\end{array}$} & \multicolumn{2}{|c|}{$\begin{array}{l}\text { Comparison } \\
(n=36)\end{array}$} \\
\hline & $M$ & $S E$ & $M$ & $S E$ & $M$ & $S E$ & $M$ & $S E$ \\
\hline Satisfaction With Life & $4.33_{\mathrm{a}}$ & 0.31 & $3.86_{\mathrm{b}}$ & 0.30 & $4.97_{c}$ & 0.30 & $4.67_{\mathrm{a}, \mathrm{c}}$ & 0.15 \\
\hline Positive affect & $3.08_{\mathrm{a}}^{\mathrm{a}}$ & 0.16 & $3.10_{\mathrm{a}}$ & 0.15 & $2.99^{\mathrm{c}}$ & 0.15 & $3.15_{\mathrm{a}}^{\mathrm{a}, \mathrm{c}}$ & 0.13 \\
\hline Negative affect & $1.56_{\mathrm{a}}^{\mathrm{a}}$ & 0.11 & $1.46_{\mathrm{a}}^{\mathrm{a}}$ & 0.11 & $1.53_{\mathrm{a}}^{\mathrm{a}}$ & 0.11 & $1.60_{\mathrm{a}}$ & 0.11 \\
\hline Overall health & $84.88_{\mathrm{a}}^{\mathrm{a}}$ & 1.36 & $85.72_{\mathrm{a}}^{\mathrm{a}}$ & 1.35 & $85.20 \mathrm{a}$ & 1.30 & $84.45_{\mathrm{a}}^{\mathrm{a}}$ & 1.17 \\
\hline Physical Functioning & $97.34_{\mathrm{a}}^{\mathrm{a}}$ & 2.04 & $98.05_{\mathrm{a}}^{\mathrm{a}}$ & 2.03 & $94.66_{a}^{a}$ & 1.96 & $96.54_{a}^{a}$ & 1.39 \\
\hline Pain & $80.05_{\mathrm{a}}$ & 3.46 & $80.999_{\mathrm{a}}$ & 3.36 & $78.85_{\mathrm{a}}^{\mathrm{a}}$ & 3.31 & $77.35_{\mathrm{a}}$ & 2.38 \\
\hline Role Functioning & $95.36_{\mathrm{a}}^{\mathrm{a}}$ & 2.22 & $99.18_{\mathrm{a}}^{\mathrm{a}}$ & 2.19 & $96.90_{\mathrm{a}}^{\mathrm{a}}$ & 2.13 & $95.79_{\mathrm{a}}^{\mathrm{a}}$ & 1.50 \\
\hline Social Functioning & $95.67_{\mathrm{a}}^{\mathrm{a}}$ & 1.72 & $98.21_{\mathrm{a}}^{\mathrm{a}}$ & 1.68 & $97.32_{\mathrm{a}}^{\mathrm{a}}$ & 1.65 & $96.80^{a}$ & 1.65 \\
\hline Mental Health & $69.89 \mathrm{a}$ & 1.81 & $69.19 \mathrm{a}$ & 1.78 & $68.98_{\mathrm{a}}$ & 1.74 & $75.044_{a}$ & 1.79 \\
\hline Health Perceptions & $69.88_{\mathrm{a}}^{\mathrm{a}}$ & 3.17 & $76.09_{\mathrm{a}}^{\mathrm{a}}$ & 3.10 & $78.97_{\mathrm{a}}^{\mathrm{a}}$ & 3.05 & $65.32_{\mathrm{a}}^{\mathrm{a}}$ & 2.99 \\
\hline Physical Symptoms & $1.66_{\mathrm{a}}^{\mathrm{a}}$ & 0.09 & $1.57_{\mathrm{a}}^{a}$ & 0.09 & $1.66_{\mathrm{a}}$ & 0.09 & $1.62_{\mathrm{a}}^{\mathrm{a}}$ & 0.06 \\
\hline
\end{tabular}

Note. High scores indicate increasing functioning, except for negative affect and physical symptoms. Means that share subscripts are not significantly different from one another. The means for the thinking group for satisfaction with life are significantly different from those of the talking and writing groups (combined) 
emotions. On the basis of this assumption, we expected those who thought about their happiest experience to report more favorable outcomes than those who analyzed it through writing or talking. Support for this hypothesis was lacking for health, but it was found for one important outcome variable-namely, life satisfaction. That is, private thought about a positive life event was associated with higher satisfaction with life than writing or talking about that event. Furthermore, although inspection of the means suggests that comparison group participants reported higher life satisfaction than did writers and talkers but lower life satisfaction than did thinkers, these group differences did not reach statistical significance. Thus, we cannot conclude whether the effects on life satisfaction were due to the thinking condition producing a favorable outcome (relative to no-treatment controls) versus the talking and writing conditions producing a relatively unfavorable outcome.

As in Study 1, thinking did not differentially affect transient mood. Although this null finding appears to challenge our argument that thinking privately about happy moments maintains PA, we speculate that the 4-week interval between our assessments of transitory mood limited the possibility of finding significant differences. However, our findings with regard to life satisfaction-a construct that incorporates PA and positive self-judgments-are indeed consistent with the maintenance-of-PA argument.

\section{STUDY 3}

Our next step was to investigate the mechanisms underlying the effects of processing positive events-that is, repetitive replay versus systematic analysis. To this end, in Study 3, we examined the role of replaying versus analysis in producing differential outcomes for long-term PA, aspects of psychological well-being, and physical health by using an experimental controlled design. ${ }^{4}$ On the basis of previous research, we hypothesized that those who wrote about a positive life experience while systematically analyzing it would show the least favorable outcomes of all our groups, whereas those who thought about a positive life experience while repetitively replaying it would show the most favorable outcomes.

\section{Method \\ Participants}

One hundred twelve ( 65 female, 47 male) undergraduate students at the University of California, Riverside, participated in this study. Over half of the participants were of Asian (32\%) or Latino(a) (31\%) descent, $21 \%$ were Caucasian, 6\% were African American, and $10 \%$ identified themselves as "other." Students ranged in age from 17 to 29 years $(M=19.23$ years, $S D=2.03$ years). Participants were again matched across conditions for gender. Four additional participants failed to complete all the sessions of the study and were not included in the analyses.

\section{Procedure}

In this study, half of the participants were randomly assigned to think about one of their happiest days, and half were assigned to write about it. Furthermore, half were induced to repetitively replay the day while thinking or writing, and half were induced to systematically analyze it. Consequently, four experimental conditions were created — that is, thinking while replaying $(n=30)$, thinking while analyzing $(n=29)$, writing while replaying $(n=27)$, and writing while analyzing $(n=26)$. A no-treatment control group was not used in this study, as it was not necessary to test our central hypotheses.

As in the first two studies, participants were required to complete four separate sessions-three sessions on consecutive days (i.e., Day 1, Day 2, and Day 3) and the fourth session (i.e., Day 4) approximately 4 weeks later. Furthermore, a packet of outcome measures was administered on Day 1 (the 1st day of the study and prior to assignment to one of the four manipulations) and Day 4 (4 weeks subsequent to completing the first packet).

\footnotetext{
${ }^{4}$ In Studies 1 and 2, we attempted a preliminary examination of the mechanisms underlying the observed effects through an analysis of the written and spoken words generated over the course of the 3 days. To this end, judges coded the percentage of writing or speech for (a) the amount of systematic, step-by-step analysis of the positive or negative experience and (b) the amount of replaying or recounting of that experience. Interrater reliability was modest to good for both types of ratings in both studies ( $\alpha \mathrm{s}$ from .50 to .79). Furthermore, in each study, we ran a proxy sample of participants who experienced our thinking condition (albeit, for 1 day only) and then estimated the percentage of their allotted time that they spent replaying versus analyzing the event.

Because the organized and systematic nature of both writing and talking lends itself to greater step-by-step analysis and reduced repetitive, chaotic replaying, we expected participants who were induced to write or talk to engage in increasingly more analysis and less replaying of the experience over the course of the 3-day induction. Supporting this argument, repeated measures analyses revealed that the amount of time spent analyzing increased over the course of the 3 days for the writing group in both studies-Study $1, F(1,18)=34.91, p<.0001, \eta=.81$; Study $2, F(1$, $14)=14.86, p<.001, \eta=.72$ - whereas replaying decreased-Study 1 , $F(1,18)=34.17, p<.0001, \eta=.81$; Study $2, F(1,14)=14.86, p<.001$, $\eta=.72$. Students who talked out loud showed similar-though not all significant-trends, such that replaying decreased over the 3-day periodStudy $1, F(1,10)=4.00, p=.07, \eta=.53$; Study $2, F(1,8)=21.31, p<$ $.001, \eta=.85$-whereas analyzing generally increased-Study $1, F<2$; Study $2, F(1,8)=13.83, p<.01, \eta=.80$.

When asked what percentage of the designated $15 \mathrm{~min}$ they spent replaying versus analyzing their happy or unhappy life event, proxy (1-day) participants reported in both studies that they had spent a little more than half the time ( $M=53.6 \%$ in Study $1 ; M=54.1 \%$ in Study 2$)$ replaying and a little less than half the time analyzing ( $M=46.2 \%$ in Study $1 ; M=$ $44.5 \%$ in Study 2).

Finally, we tested whether the more analysis students engaged in during writing and talking, the more beneficial outcomes they accrued 4 weeks later. In Study 1, regression analyses using data from the writing group revealed that greater percentages of time students were coded as systematically analyzing their negative experience (and the less time they spent replaying) were associated with higher transient PA, $F(1,18)=5.32, p=$ $.03, \eta=.48$; lower NA, $F(1,18)=8.44, p<.009, \eta=.56$; better overall mental health, $F(1,18)=7.65, p=.01, \eta=.55$; better overall health, $F(1$, 18) $=9.29, p<.01, \eta=.58$; and better health perceptions, $F(1,18)=$ $9.61, p<.01, \eta=.59$. These findings support the premise that systematically analyzing (i.e., writing about) a negative life experience is more beneficial than replaying or repetitively processing the experience (as when thinking about it). Unfortunately, possibly because of technical and coding difficulties, the same pattern of results was not observed in codings of the speech samples generated in the talking condition. In Study 2, neither replaying nor analysis was found to be related to the outcome variables when participants processed a happy experience by writing or talking about it $($ all $F \mathrm{~s}<2, n s)$
} 


\section{Outcome Measures}

\section{Long-Term PA}

In place of the SWLS, we used a measure of long-term, or dispositional, PA. Long-term PA is assessed with the PANAS (Watson et al., 1988), but instead of rating their current experience, participants were instructed to rate the extent they had "felt this way during the last 3 months." The reliabilities for this scale were very good $(\alpha \mathrm{s}=.84$ and .89 for long-term $\mathrm{PA}$, and $\alpha \mathrm{s}=.88$ and .89 for long-term NA). In previous studies, long-term PA has correlated strongly with the SWLS, with $r$ s ranging from the .30 s to the .60 s (e.g., Tkach, 2005).

\section{Psychological Well-Being}

For a multidimensional assessment of well-being, we implemented the Psychological Well-Being Scale (PWB; Ryff, 1989), an 84-item assessment of positive functioning ( $\alpha \mathrm{s}=.96$ and .98 for Time 1 and Time 2, respectively). The PWB consists of six major subscales-Autonomy, Environmental Mastery, Personal Growth, Positive Relations With Others, Purpose in Life, and Self-Acceptance. All PWB items are rated on the same 6-point Likert-type scale ( 1 = strongly disagree, 6 = strongly agree $)$.

The Autonomy subscale of the PWB consists of such items as "My decisions are not usually influenced by what everyone else is doing." An example of the Mastery subscale is "I am quite good at managing the many responsibilities of my daily life." The Personal Growth subscale asks such questions as "For me, life has been a continuous process of learning, changing, and growth." An example of the Positive Relations With Others subscale is "I feel like I get a lot out of my friendships." The Purpose in Life subscale contains such items as "I have a sense of direction and purpose in life." Finally, the Self-Acceptance subscale includes such statements as "In general, I feel confident and positive about myself." In the past, the PWB has displayed good psychometric properties, with internal consistency for all six subscales ranging between .86 and .93 (Ryff, 1989).

\section{Physical Health}

With the exception of the Symptoms Checklist (which was excluded), the same measures of health $(\alpha \mathrm{s}=.88$ [Time 1] and .89 [Time 2] for the Health Survey) used in the first two studies were administered in Study 3.

\section{Experimental Manipulation}

\section{Happiest Day Form}

After identifying one of the happiest days they had ever experienced, participants completed the same Life Experience Questionnaire used in the previous two studies.

\section{Experimental Conditions}

Next, participants were exposed to one of four experimental manipulations for exactly 8 min a day over a 3-day period.

Think-replay condition. In this condition, students were asked to simply think about their positive life experience strictly by replaying their thoughts over and over again. Prior to beginning their first session, participants were given an instructional packet containing the following instructions:

Please spend the next 8 minutes privately thinking about the day you described on the previous page. Please replay these thoughts as though you were rewinding a videotape and playing it back. Think about the events of the day with an emphasis on what happened, how you were feeling at the time, and how you behaved. The following pages will contain questions/instructions that should help you through this thought process. . . . Feel free to move from page to page at your own leisure and to skip over any questions that you feel do not particularly pertain to your experience.

Once participants confirmed that they understood these instructions, they were left to contemplate the following statement and questions, which were printed on five separate pages:

Remember exactly what happened in as much detail as you can Think about: What exactly did you do or say?

Think about: If another person (or people) were involved, what exactly did they do or say?

Think about: How did you feel about this experience at the time it occurred?

Think about: How did you feel about yourself following this experience?

Participants returned to these instructions on Day 2 and Day 3.

Think-analyze condition. In this condition, participants were asked to think about their positive life experience by systematically analyzing their thoughts. The instructional packet they received was identical to that used in the think-replay condition, except for the first few sentences, which read as follows:

Please spend the next 8 minutes privately thinking about the day you described on the previous page. Please try to analyze your thoughts by doing a step-by-step breakdown of the events of the day from the beginning to the end. Ask yourself such questions as "why" or "how" did this experience happen to me. Use your time thinking about the experience in an effort to understand it and to make sense of why this experience might have happened to you.

Next, participants in this condition were left to contemplate the following statement and questions, printed on five separate pages:

Analyze the events of the day in a step-by-step manner from beginning to end, with an emphasis on "why" and "how" this experience happened to you.

Think about: In what ways could this happy event be viewed differently?

Think about: What could you have done differently to change the course of the event?

Think about: What would you do or say differently if you could reexperience this event again?

Think about: Do you think others would feel the same way if they experienced the same thing you did? Explain your response.

Write-replay condition. In this condition, participants were asked to write about their positive life experience by replaying the experience over and over again as though rewinding a tape and replaying it. Students were given a standard blue book to record their writing and were asked to return to this blue book on each of the 3 consecutive days of their participation. In addition to receiving this "journal," participants were provided an instructional packet that was identical to that of the think-replay condition save the one novel instruction to write instead of think.

Write-analyze condition. In this condition, participants were asked to write about their positive life experience by systematically analyzing the event. Again, students were given blue books to record their writing and were referred to an instructional packet identical to that of the thinkanalyze condition except for the one novel instruction to write instead of think.

\section{Follow-Up}

Four weeks subsequent to their participation in one of the four conditions, all participants returned to the laboratory to complete their final day 
of participation in the study. Upon arrival, participants were asked to complete the same packet of outcome measures they received on Day 1.

\section{Results}

\section{Overview of Statistical Analyses}

In this study, participants' long-term affect, psychological wellbeing, and health were assessed before and after they processed one of their happiest moments. Similar to the first two studies, the extent to which participants' scores on these variables changed as a result of exposure to one of our four conditions was examined by analyzing Time 2 data with Time 1 as a covariate.

The reader will recall that, out of all our groups, students in the think-replay group were expected to reap the greatest benefits for their happiness and health, whereas those in the write-analyze group were expected to show the poorest results. Although, theoretically, replaying should produce relatively favorable outcomes, and analysis should produce unfavorable outcomes, no matter what the mode of processing (i.e., writing, talking, thinking), we could not make clear predictions regarding the outcomes of the two mixed conditions-namely, write-replay and think-analyze-as each involved two manipulations predicted to have opposite effects on happiness and health.

To test our primary hypotheses, we performed planned contrasts (with Time 1 variables as a covariate) by comparing the writeanalyze group and the think-replay group, respectively, to the remaining three conditions. These two hypotheses combined led to the prediction that writers who analyzed would benefit significantly less from our study than thinkers who replayed. This hypothesis was tested by performing a planned pairwise comparison directly between the write-analyze group and the think-replay group.

\section{Ratings of Positive Life Experiences}

Examples of happiest days named by participants included a day spent with the object of one's love, the day of one's high school graduation, and a thrilling vacation day. On average, students indicated that their happy day had occurred somewhere between 3 months and 6 months ago $(M=4.47$ on a 10 -point scale) and that the event had been highly significant to them $(M=8.93$ on a 9-point scale). Furthermore, participants indicated that they had previously spent a fair amount of time thinking about the positive experience ( $M=6.69$ on a 10 -point scale) and relatively little time writing about it ( $M=3.28$ on a 10-point scale). As expected, a series of Tukey's HSD post hoc analyses revealed no significant differences among the four experimental groups for any of these variables prior to manipulation.

\section{Manipulation Checks}

\section{Staying on Task}

Analyses were also conducted to establish group differences in participants' ability to stay on task during the timed manipulation. Overall, students reported that they spent over 6 of the $8 \mathrm{~min}$ allotted to them each day focused on the task at hand $(M=6.38$ min out of 8). Post hoc analyses did reveal significant differences among the four experimental groups on this variable, $F(3,108)=$ 21.97, $p<.001, \eta=.41$. That is, the write-analyze group spent the most time focused on the task $(M=7.38 \mathrm{~min})$, followed by the write-replay group $(M=7.33 \mathrm{~min})$, the think-analyze group $(M=$ $5.55 \mathrm{~min})$, and then the think-replay group $(M=5.47 \mathrm{~min})$. The act of writing - a systematic and organized process - may have kept students more focused on the task than did the act of thinking - a loose and somewhat chaotic process that can lead to mind wandering.

With regard to reported difficulty staying on task, participants on average indicated that it was fairly easy to concentrate on the task ( $M=2.83$ on a 7-point scale). Post hoc analyses again revealed significant group differences on this variable, $F(3,108)=$ $7.67, p<.001, \eta=.26$. That is, the think-analyze group had the most difficulty staying on task $(M=3.66)$, followed by the think-replay group $(M=3.30)$, the write-replay group $(M=$ $2.30)$, and then the write-analyze group $(M=1.92)$. This finding may again be due to the more focused nature of writing as compared with thinking.

In light of these differences in each group's ability to maintain focus, we conducted covariance analyses by using both time spent on task and difficulty staying on task each day as a covariate. The results of those analyses were virtually identical to our original results.

\section{Condition Compliance}

To verify that our participants had complied with our instructions to either replay or analyze their happiest day, three judges subsequently coded the narratives generated by participants in the two writing conditions. For obvious reasons, participants' thoughts in the two thinking conditions could not be similarly coded.

In sum, participants' written essays were coded to determine the percentage of repetitive replay versus systematic analysis that actually appeared in the writing $(\alpha=.84$; see Footnote 4 for coders' instructions). The average of judges' ratings indicated that participants in the replay condition engaged in replaying $69 \%$ of the time and engaged in analysis $31 \%$ of the time, whereas those in the analyze condition engaged in analysis $57 \%$ of the time and in replaying $43 \%$ of the time. This group difference was statistically significant, $t(51)=3.83, p<.001, \eta=.26$.

\section{Outcome Measures}

Again, the relevant statistics for all outcome variables are presented in a single table (see Table 3 ).

\section{Long-Term PA}

A planned contrast revealed that the think-replay group had the highest long-term PA relative to all the other groups $(M \mathrm{~s}=3.63$ vs. 3.41$), F(1,107)=2.22, p=.07, \eta=.14$. This finding is consistent with our hypothesis that repetitively replaying one's happiest life experience while privately thinking about it would maintain the positive emotions that surround it, thus producing the greatest benefits for an individual's well-being. Other planned comparisons with the affect variable failed to reach conventional levels of statistical significance.

\section{Psychological Well-Being}

Participants who wrote while analyzing their happiest day were expected to report decreased psychological well-being, whereas 
Table 3

Marginal Means (Adjusted for Time 1) and Standard Errors for Processing Positive Experiences by Condition (Study 3)

\begin{tabular}{|c|c|c|c|c|c|c|c|c|}
\hline \multirow[b]{3}{*}{ Measure } & \multicolumn{8}{|c|}{ Condition } \\
\hline & \multicolumn{2}{|c|}{$\begin{array}{l}\text { Think-replay } \\
\quad(n=30)\end{array}$} & \multicolumn{2}{|c|}{$\begin{array}{l}\text { Think-analyze } \\
\quad(n=29)\end{array}$} & \multicolumn{2}{|c|}{$\begin{array}{l}\text { Write-replay } \\
\quad(n=27)\end{array}$} & \multicolumn{2}{|c|}{$\begin{array}{l}\text { Write-analyze } \\
\quad(n=26)\end{array}$} \\
\hline & $M$ & $S E$ & $M$ & $S E$ & $M$ & $S E$ & $M$ & $S E$ \\
\hline Long-term PA & $3.63_{\mathrm{a}}$ & 0.12 & $3.43_{\mathrm{b}}$ & 0.12 & $3.39_{b}$ & 0.12 & $3.42_{\mathrm{b}}$ & 0.12 \\
\hline Long-term NA & $2.32_{\mathrm{a}}^{\mathrm{a}}$ & 0.13 & $2.26_{\mathrm{a}}$ & 0.13 & $2.30_{\mathrm{a}}$ & 0.13 & $2.18_{\mathrm{a}}$ & 0.13 \\
\hline Overall PWB & $4.52_{\mathrm{a}}$ & 0.07 & $4.61_{\mathrm{a}}^{\mathrm{a}}$ & 0.07 & $4.59 \mathrm{a}$ & 0.07 & $4.47_{\mathrm{a}}^{\mathrm{a}}$ & 0.07 \\
\hline Autonomy & $4.23_{\mathrm{a}}$ & 0.08 & $4.36_{\mathrm{a}}$ & 0.08 & $4.35_{\mathrm{a}}^{\mathrm{a}}$ & 0.09 & $4.37_{\mathrm{a}}^{\mathrm{a}}$ & 0.09 \\
\hline Positive Relations With Others & $4.55_{\mathrm{a}}^{\circ}$ & 0.09 & $4.64_{\mathrm{a}}^{\circ}-2-3$ & 0.09 & $4.66_{\mathrm{a}}^{\mathrm{a}}$ & 0.09 & $4.61_{\mathrm{a}}$ & 0.09 \\
\hline Purpose in Life & $4.71_{\mathrm{a}}^{a}$ & 0.10 & $4.78_{\mathrm{a}}^{\mathrm{a}}$ & 0.10 & $4.72_{\mathrm{a}}^{\mathrm{a}}$ & 0.10 & $4.65_{\mathrm{a}}^{\mathrm{a}}$ & 0.10 \\
\hline Personal Growth & $5.03_{a}^{a}$ & 0.09 & $5.02_{\mathrm{a}}^{\mathrm{a}}-\mathrm{a}-\mathrm{a}$ & 0.09 & $4.94_{\mathrm{a}}^{\mathrm{a}}$ & 0.10 & $4.76_{\mathrm{b}}^{\mathrm{a}}$ & 0.10 \\
\hline Self-Acceptance & $4.36_{\mathrm{a}}$ & 0.10 & $4.54 \mathrm{a}$ & 0.10 & $4.55_{\mathrm{a}}$ & 0.11 & $4.22_{\mathrm{b}}$ & 0.11 \\
\hline Environmental Mastery & $4.11_{\mathrm{a}}^{\mathrm{a}}$ & 0.10 & $4.40_{\mathrm{b}}^{\mathrm{a}}$ & 0.10 & $4.30_{\mathrm{b}}^{\mathrm{a}}$ & 0.11 & $4.30_{\mathrm{b}}$ & 0.11 \\
\hline Overall health & $82.03_{\mathrm{a}}$ & 1.34 & $82.57_{\mathrm{a}}$ & 1.36 & $80.82_{\mathrm{a}}$ & 1.41 & $79.06_{\mathrm{b}}$ & 1.44 \\
\hline Physical Functioning & $97.47_{\mathrm{a}}^{\mathrm{a}}$ & 1.34 & $97.38_{\mathrm{a}}^{\mathrm{a}}$ & 1.36 & $96.65_{\mathrm{a}}^{\mathrm{a}}$ & 1.41 & $93.95_{\mathrm{b}}$ & 1.43 \\
\hline Pain & $76.90_{\mathrm{a}}^{\mathrm{a}}$ & 3.54 & $78.06_{\mathrm{a}}^{\mathrm{a}}$ & 3.54 & $71.07_{\mathrm{a}}^{\mathrm{a}}$ & 3.67 & $64.90_{\mathrm{b}}$ & 3.75 \\
\hline Role Functioning & $93.86_{\mathrm{a}}^{\mathrm{a}}$ & 2.75 & $97.17_{\mathrm{a}}^{\mathrm{a}}$ & 2.80 & $87.96_{a}^{a}$ & 2.90 & $94.00_{\mathrm{a}}$ & 2.96 \\
\hline Social Functioning & $88.71_{\mathrm{a}}^{\mathrm{a}}$ & 4.60 & $92.42_{\mathrm{a}}^{\mathrm{a}}$ & 4.66 & $90.38_{\mathrm{a}}^{\mathrm{a}}$ & 4.84 & $86.86_{\mathrm{a}}^{\mathrm{a}}$ & 4.94 \\
\hline Mental Health & $64.95_{\mathrm{a}}^{\mathrm{a}}$ & 3.17 & $66.18_{\mathrm{a}}^{\mathrm{a}}$ & 3.20 & $64.80_{\mathrm{a}}^{\mathrm{a}}$ & 3.32 & $64.87_{\mathrm{a}}^{\mathrm{a}}$ & 3.39 \\
\hline Health Perception & $74.45_{\mathrm{a}}^{\mathrm{a}}$ & 2.40 & $74.35_{\mathrm{a}}^{\mathrm{a}}$ & 2.42 & $74.91_{\mathrm{a}}^{\mathrm{a}}$ & 2.51 & $72.03_{\mathrm{a}}^{\mathrm{a}}$ & 2.56 \\
\hline
\end{tabular}

Note. Except for NA, high scores indicate increasing functioning. Means for three groups that share subscripts (combined) are significantly different from the mean of the fourth group (with different subscript). The means of the think-replay group and the write-analyze group are significantly different for (a) personal growth, (b) overall health, (c) physical functioning, and (d) pain. PA = positive affect; NA = negative affect; PWB = Psychological Well-Being Scale.

those who thought while replaying this day were expected to show increased well-being. However, these predictions were not supported for our overall measure of psychological well-being, and analyses involving the six subscales proved to have mixed results. That is, two of the subscales for PWB (Personal Growth and Self-Acceptance) did provide support for our propositions, whereas one subscale (Environmental Mastery) revealed an unexpected finding. No group differences were found for Autonomy, Purpose in Life, and Positive Relations With Others.

Personal growth. As shown in Table 3, a planned contrast, with Time 1 personal growth as a covariate, indicated that the write-analyze group reported less personal growth relative to the three other groups combined $(M \mathrm{~s}=4.76$ vs. 5.00$), F(1,107)=$ $4.59, p=.02, \eta=.20$. No significant group differences were found when the think-replay condition was compared with the remaining three conditions, $F(1,107)=1.42$, ns. However, writers who analyzed reported decreased personal growth relative to thinkers who replayed, $F(1,107)=4.22, p=.02, \eta=.19$.

Self-acceptance. A planned contrast, with Time 1 selfacceptance as a covariate, showed that participants in the writeanalyze group reported less self-acceptance relative to the remaining $\operatorname{groups}(M \mathrm{~s}=4.22$ vs. 4.48), $F(1,107)=4.76, p=.02, \eta=$ .21. No other significant group differences emerged $\left(F_{\mathrm{s}}<1\right)$.

Environmental mastery. Contrary to our predictions, the think-replay group reported marginally significant decreases in environmental mastery relative to the other groups $(M \mathrm{~s}=4.11$ vs. 4.33), $F(1,107)=-3.12, p=.08, \eta=-.17$.

\section{Health Survey}

Overall health. The poorest general health at Time 2 was expected for participants who wrote about their happiest day while analyzing it, and the best general health was expected for those who thought privately about their happiest day while replaying it. Supporting this hypothesis, a planned contrast, with Time 1 health as a covariate, as measured by the overall Health Survey, revealed significantly lower health at Time 2 for the write-analyze group relative to the think-replay, think-analyze, and write-replay groups combined $(M \mathrm{~s}=79.06$ vs. 81.83), $F(1,107)=2.90, p=$ $.05, \eta=.16$. Yet no significant differences in health were found when comparing the think-replay group with the remaining three conditions $(F<1, n s)$. However, when compared directly with one another, the write-analyze group showed marginally significant decline in health relative to the think-replay group, $F(1,107)=$ 2.32, $p=.07, \eta=.15$.

Because the measure of health used in this study comprised six subscales, further analyses could examine more specific aspects of general health. These analyses revealed that several of our hypotheses were supported for two of these subscales-Physical Functioning and Pain. No significant group differences were found for the remaining four subscales-Health Perceptions, Role Functioning, Social Functioning, and Mental Health (see Table 3).

Physical functioning. Planned contrasts with Time 1 physical functioning as a covariate revealed that the write-analyze group reported decreased physical functioning relative to the other groups combined $(M \mathrm{~s}=93.95$ vs. 97.18), $F(1,107)=3.90, p=$ $.03, \eta=.19$, but the think-replay group did not report increased physical functioning relative to the other groups $(F<1, n s)$. Finally, participants who wrote while analyzing reported diminished physical functioning relative to those who thought while replaying, $F(1,107)=3.26, p=.04, \eta=.17$.

Pain. In addition to finding some support for our hypotheses regarding reported physical functioning, we found that the write- 
analyze group also reported more pain relative to the think-replay, think-analyze, and write-replay groups $(M \mathrm{~s}=64.90$ vs. 75.30$)$, $F(1,107)=5.90, p<.01, \eta=.23$, and the think-replay group reported less pain relative to the other three groups $(M \mathrm{~s}=76.90$ vs. 71.34), $F(1,107)=1.85, p=.09, \eta=.13$, although this difference was nonsignificant. Finally, writers who analyzed their happiest moments reported greater pain than thinkers who replayed those moments, $F(1,107)=5.42, p=.01, \eta=.22$.

\section{Discussion}

We expected individuals who wrote analytically about one of their happiest life moments to report less favorable outcomes (e.g., reduced affect, well-being, and health) relative to those who thought repetitively about such experiences. Modest support for our specific predictions was found for several of the outcome variables, including long-term PA, personal growth, selfacceptance, overall health, physical functioning, and pain.

First, supporting our hypothesis, relative to the other conditions, our results showed that thinking while replaying one's happiest day yielded significantly enhanced long-term PA and, to some extent, decreased pain. This finding is consistent with the notion that repetitive, cyclical thoughts about happy experiences maintain positive emotions. Second, as predicted, writing while analyzing led to reduced personal growth, self-acceptance, general health, and physical functioning and to increased reported pain. Finally, thinking while replaying one's happiest moment was associated with superior personal growth, general health, and physical functioning - and with lower pain - than writing while analyzing that moment.

It is interesting to note one finding that was unexpected and contrary to our predictions: Students induced to think while replaying their happiest moments actually reported decreased feelings of environmental mastery relative to the other groups. This finding is particularly difficult to interpret given that thinking while replaying simultaneously produced increased long-term PA relative to these same groups. Perhaps repetitively replaying happy memories in one's mind helps to maintain or increase the positive feelings associated with those events, but also impairs one's ability to self-regulate. As previously discussed, self-regulation is one of the proposed mechanisms thought to account for the benefits of trauma writing. Conceivably, then, it is this lack of self-regulatory processing-occurring when people are thinking and especially when they are thinking while repetitively replaying - that may have impaired rather than improved at least one aspect of wellbeing (i.e., environmental mastery). Additionally, because having a sense of mastery often involves analysis of one's performance and potential for improvement, this sense may be inhibited by unsystematic replaying. Further research is needed to test these arguments empirically.

In conclusion, the results of Study 3 provide some evidence that writing while systematically analyzing positive experiences is more deleterious to well-being and health than thinking while repetitively replaying these experiences. These findings suggest that breaking down one's happiest moments through writing-a process that seems to create a detailed narrative analysis-should perhaps be avoided, even though the very same process appears to be useful when applied to negative life events. Furthermore, when it comes to happy life experiences, our modest evidence indicates that perhaps people ought not to overanalyze or attempt to make sense of why and how a fortunate circumstance has befallen them. Instead, perhaps people should simply be content to relive and savor these experiences without trying to determine their causes or meanings (Bryant, 2003; Wilson et al., 2005). Additional work is needed to further bear out and clarify this interesting phenomenon.

\section{GENERAL DISCUSSION}

\section{Study 1: Negative Life Experiences}

We hypothesized that students who wrote or talked into a tape recorder about their worst life experience would report improved life satisfaction and health relative to participants who thought privately about the experience. This hypothesis was generally supported. The only outcome variable that did not show this pattern of results was transient affect, which may fluctuate too much to expect stable changes 4 weeks after the induction.

Previous research on the relationship between cognition and health has provided evidence for substantial benefits of writing and talking about traumatic events (DeLongis et al., 1988; Murray \& Segal, 1994; Pennebaker, 1993). This body of work has generated speculation concerning the mechanisms by which writing and talking about one's experiences lead to positive outcomes. For example, Pennebaker has suggested that writing and talking require organization and structure, which allow individuals to let go and move past their problems, resulting in improved mental and physical health (Pennebaker, 1993; Pennebaker \& Francis, 1996). Our first study not only provided evidence for this assumption, but went beyond earlier research by directly comparing writing and talking (which presumably involve analytical processing of a traumatic experience) with private thought (which we assume to involve repetition or replaying). Thinking was predicted to be detrimental to well-being and health because it can quickly and easily degrade into negative repetitive cognitions that are relatively more difficult to integrate, condemning the person to the reexperience and maintenance of painful memories. The findings of Study 1 were consistent with this position, supporting the argument that the inherently organized nature of writing and talking about one's thoughts about a traumatic life experience may provide a way for participants to accept their experiences and record them in an external fashion, thus allowing them to move beyond their troubles and ultimately resulting in favorable outcomes.

\section{Positive Life Experiences}

\section{Study 2: Writing and Talking Versus Thinking}

In Study 2, we hypothesized that the organized and systematic nature of writing and talking may be somewhat incompatible with the maintenance of PA and might therefore interfere with the potential benefits associated with the experience of positive emotion (Fredrickson, 2001). These hypotheses were supported in this study for satisfaction with life. Participants who thought privately about their happiest experience reported greater life satisfaction than participants who wrote or talked about such an experience.

It may be too early in this research endeavor to understand completely why thinking about a positive event would improve life satisfaction but not show similar outcomes for physical health. However, a consideration of the construct of life satisfaction may provide some clues. The assessment of satisfaction with life involves measures that tap beliefs and perceptions of one's own life 
and one's emotions and feelings. Writing and talking (analytical processes) about a positive experience may lead one down a path of evaluation and seeking meaning that is incompatible with sustaining positive emotion and, therefore, incompatible with positive beliefs about oneself and one's circumstances. That is, because life satisfaction comprises one's beliefs and feelings, this measure may be more sensitive to any changes one might experience from processing experiences in systematic and analytical ways. In contrast, the measures of physical health and health symptoms are relatively more likely to tap behavior and physiology and, thus, are perhaps less sensitive to experimental manipulation when writing, talking, and thinking about positive experiences are involved. The lack of specific instructions about exactly how participants should write, talk, and think might contribute to this relative lack of sensitivity. Future research using more finely tuned physiological and behavioral measures is needed to further clarify these findings.

\section{Study 3: Analysis Versus Replaying}

Our first two studies raised the question of mechanisms, and Study 3 aimed to address this question. Specifically, Study 3 manipulated the precise ways that people write or think about significant events. We found modest support for the hypothesis that individuals induced to write about a happy life event in an analytic fashion would report poorer well-being and physical health relative to those induced to process the same event by simply rehearsing and replaying it in their thoughts. These findings suggest that when considering positive experiences, it is the inherently organized, narrative-based, and analytic nature of writing that may be counterproductive to well-being and health. In contrast, at least with respect to the maintenance of PA, the repetitive, circular, inherently unorganized nature of thought is beneficial. Recalling a wonderful moment-a triumph, a creative breakthrough, a first declaration of love-by reliving it through rehearsal and replaying may allow the individual to savor (Bryant, 1989, 2003) and capitalize on (Gable et al., 2004; Langston, 1994) the experience. Furthermore, reviewing a happy event-without sense making or analysis-helps the person retain a sense of mystery and thrill about the event (Wilson et al., 2005; Wilson \& Gilbert, 2003). In sum, we believe these processes act to maintain and bolster positive emotions, which contribute to a person's overall physical and emotional well-being (Fredrickson, 2001).

Achieving a sense of meaning, resolution, and control over significant past life experiences has long been held to have enormous value. Our research introduces a potential caveat to this recommendation-that is, that it may apply only to those experiences that are negative. As G. K. Chesterton (1905) asserted, "Happiness is a mystery like religion, and should never be rationalized" (p. 103). Future studies that replicate and advance our findings would be much desired.

\section{Limitations and Future Questions}

Several limitations related to design and data collection should be mentioned. Because all of our outcomes in our three studies were measured via self-report, we must be vigilant of social desirability and response biases. However, we believe that the participants themselves are our best resources for information about their own emotions and cognitions. It is also worth noting that any weakness or unreliability in our measures would presum- ably serve to increase error variance and thus would tend to obscure differences that might be seen more clearly with more discriminating measures. However, future research would be strengthened by using other means of assessment, including physiological measures (e.g., heart rate, blood pressure, skin conductance, white blood cell count, and antibody and cortisol levels) and behavioral measures (e.g., number of doctor visits and direct observations of activity level) as well as reports from knowledgeable informants.

Another concern is about the generalizability of our results beyond a student sample. The average age of our participants in these three studies was approximately 19 years. The relatively modest life experience of this age group may have influenced the strength of the effects, making it relatively difficult to predict the impact of the different ways of event processing on older adults who may have endured greater hardships (e.g., poor health, divorce, or financial problems) or greater joys (e.g., wedding, birth of a child, or career success). However, experiences and the emotions surrounding them are relative. One's experience of an event is anchored by one's prior experiences. It could be argued that a first love could be just as thrilling and significant as getting married and having a child might be to someone else with more maturity and resources.

The present studies have begun to establish some differential benefits and drawbacks of processing positive and negative events-life's victories and defeats. However, an investigation that compares the processing of positive and negative experiences in a single study would be needed to answer a variety of questions. For example, is writing analytically about a trauma a superior practice than thinking repetitively about a triumph? Is analyzing a positive event more harmful to one's well-being and functioning than replaying a negative one? Answers to these questions may provide practical suggestions concerning the healing effects of managing traumatic versus joyful events.

\section{Concluding Remarks}

Our research suggests that systematic step-by-step analysis (which presumably tends to occur while writing or speaking) is worthwhile and beneficial when directed at unhappy, stressful, or traumatic life events, but may be harmful when applied to happy times. In contrast, repetitive, circular replaying (which presumably is inclined to occur during private thought) is somewhat advantageous when the target is one's highest moment, but may be damaging when the target is one's lowest ebb. Prior research has almost exclusively focused on how people process negative experiences and has generated a remarkably consistent pattern of results. By contrast, our findings highlight how a positive psychological approach can reveal previously undetected mechanisms underlying the existing evidence and, we hope, galvanize further research.

Both negative and positive life experiences undoubtedly greatly impact people's happiness, mental health, and physical well-being. However, this impact is rarely long-term, in large part due to hedonic adaptation (Frederick \& Loewenstein, 1999), but also due to people's remarkable capacity to cope with and process the events and circumstances of their lives. A greater understanding of how best to process both one's worst hours and one's most wondrous moments, how to optimize their impact on well-being and health, and how to be better for having experienced them 
would be a valuable contribution. The present research represents a first step in this direction.

\section{References}

Aspinwall, L. G., \& Brunhart, S. M. (1996). Distinguishing optimism from denial: Optimistic beliefs predict attention to health threats. Personality and Social Psychology Bulletin, 22, 993-1003.

Beck, A. T. (1967). Depression: Clinical, experimental, and theoretical aspects. New York: Harper \& Row.

Blagov, P. S., \& Singer, J. A. (2004). Four dimensions of self-defining memories (specificity, meaning, content, and affect) and their relationships to self-restraint, distress, and repressive defensiveness. Journal of Personality, 72, 481-511.

Bryant, F. B. (1989). A four-factor model of perceived control: Avoiding, coping, obtaining, and savoring. Journal of Personality, 57, 773-797.

Bryant, F. B. (2003). Savoring Beliefs Inventory (SBI): A scale for measuring beliefs about savoring. Journal of Mental Health, 12, 175-196.

Burton, C. M., \& King, L. A. (2004). The health benefits of writing about intensely positive experiences. Journal of Research in Personality, 38, $150-163$.

Chesterton, G. K. (1905). Heretics. London: Butler and Tanner.

DeLongis, A., Folkman, S., \& Lazarus, R. S. (1988). The impact of daily stress on health and mood: Psychological and social resources as mediators. Journal of Personality and Social Psychology, 54, 486-495.

Diener, E., Emmons, R. A., Larsen, R. J., \& Griffin, S. (1985). The Satisfaction With Life Scale. Journal of Personality Assessment, 49, $71-75$.

Dominguez, B., Valderrama, P., Meza, M. A., Perea, S. L., Silva, A., Martinez, G., et al. (1995). The roles of emotional reversal and disclosure in clinical practice. In J. W. Pennebaker (Ed.), Emotion, disclosure, and health (pp. 255-270). Washington, DC: American Psychological Association.

Donnelly, D. A., \& Murray, E. J. (1991). Cognitive and emotional changes in written essays and therapy interviews. Journal of Social and Clinical Psychology, 10, 334-350.

Emmons, R. A., \& McCullough, M. E. (2003). Counting blessings versus burdens: An experimental investigation of gratitude and subjective wellbeing in daily life. Journal of Personality and Social Psychology, 84, 377-389.

Esterling, B. A., L'Abate, L., Murray, E. J., \& Pennebaker, J. W. (1999). Empirical foundations for writing in prevention and psychotherapy: Mental and physical health outcomes. Clinical Psychology Review, 19, 79-96.

Foa, E., \& Riggs, D. (1993). Post-traumatic stress disorder in rape victims. In J. Oldham, M. B. Riba, \& A. Tasman (Eds.), American Psychiatric Press review of psychiatry (Vol. 12, pp. 273-303). Washington, DC: American Psychiatric Press.

Frattaroli, J. (in press). Experimental disclosure and its moderators: A meta-analysis. Psychological Bulletin.

Fredrick, S., \& Loewenstein, G. (1999). Hedonic adaptation. In D. Kahneman, E. Diener, \& N. Schwarz (Eds.), Well-being: The foundations of hedonic psychology (pp. 302-329). New York: Russell Sage Foundation.

Fredrickson, B. L. (2000, March 7). Cultivating positive emotions to optimize health and well-being. Prevention \& Treatment, 3, Article 0001a. Retrieved March 18, 2002, from http://journals.apa.org/ prevention/volume3/pre0030001a.html

Fredrickson, B. L. (2001). The role of positive emotions in positive psychology: The broaden-and-build theory of positive emotions. American Psychologist, 56, 218-226.

Fredrickson, B. L., \& Joiner, T. (2002). Positive emotions trigger upward spirals toward emotional well-being. Psychological Science, 13, 172175.

Fredrickson, B. L., \& Levenson, R. W. (1998). Positive emotions speed recovery from the cardiovascular sequelae of negative emotions. Cognition \& Emotion, 12, 191-220.
Fredrickson, B. L., Mancuso, R. A., Branigan, C., \& Tugade, M. M. (2000). The undoing effect of positive emotions. Motivation and Emotion, 24, 237-258.

Fredrickson, B. L., Tugade, M. M., Waugh, C. E., \& Larkin, G. R. (2003). What good are positive emotions in crisis? A prospective study of resilience and emotions following the terrorist attacks on the United States on September 11th, 2001. Journal of Personality and Social Psychology, 84, 365-376.

Gable, S. L., Reis, H. T., Impett, E. A., \& Asher, E. R. (2004). What do you do when things go right? The intrapersonal and interpersonal benefits of sharing positive events. Journal of Personality and Social Psychology, $87,228-245$.

Goldman, S. L., Kraemer, D. T., \& Salovey, P. (1996). Beliefs about mood moderate the relationship of stress to illness and symptom reporting. Journal of Psychosomatic Research, 41, 115-128.

Greenberg, M. A., \& Stone, A. A. (1992). Emotional disclosure about traumas and its relation to health: Effects of previous disclosure and trauma severity. Journal of Personality and Social Psychology, 63, $75-84$.

Greenberg, M. A., Wortman, C. B., \& Stone, A. A. (1996). Emotional expression and physical health: Revising traumatic memories or fostering self-regulation? Journal of Personality and Social Psychology, 71, $588-602$

Hixon, J. G., \& Swann, W. B. (1993). When does introspection bear fruit? Self-reflection, self-insight, and interpersonal choices. Journal of Personality and Social Psychology, 64, 34-43.

Holahan, C. J., \& Moos, R. H. (1985). Life stress and health: Personality, coping, and family support in stress resistance. Journal of Personality and Social Psychology, 49, 739-747.

Horowitz, M. J., Field, N. P., \& Classen, C. C. (1993). Stress response syndromes and their treatment. In L. Goldberger \& S. Breznitz (Eds.), Handbook of stress (2nd ed., pp. 757-773). New York: Free Press.

Hughes, C. F., Uhlmann, C., \& Pennebaker, J. W. (1994). The body's response to processing emotional trauma: Linking verbal text with autonomic activity. Journal of Personality, 62, 565-585.

Irving, L. M., Snyder, C. R., \& Crowson, J. J. (1998). Hope and coping with cancer by college women. Journal of Personality, 66, 195-214.

King, L. A. (2001). The health benefits of writing about life goals. Personality and Social Psychology Bulletin, 27, 798-807.

King, L. A., \& Miner, K. N. (2000). Writing about the perceived benefits of traumatic events: Implications for physical health. Personality and Social Psychology Bulletin, 26, 220-230.

Langston, C. A. (1994). Capitalizing on and coping with daily-life events: Expressive responses to positive events. Journal of Personality and Social Psychology, 67, 1112-1125.

Lyubomirsky, S., King, L. A., \& Diener, E. (2005). The benefits of frequent positive affect: Does happiness lead to success? Psychological Bulletin, 131, 803-855.

Lyubomirsky, S., \& Nolen-Hoeksema, S. (1995). Effects of self-focused rumination on negative thinking and interpersonal problem solving. Journal of Personality and Social Psychology, 69, 176-190.

Lyubomirsky, S., Sheldon, K. M., \& Schkade, D. (2005). Pursuing happiness: The architecture of sustainable change. Review of General Psychology, 9, 111-131.

Lyubomirsky, S., \& Tkach, C. (2004). The consequences of dysphoric rumination. In C. Papageorgiou \& A. Wells (Eds.), Rumination: Nature, theory, and treatment of negative thinking in depression (pp. 21-41). Chichester, England: Wiley.

Martin, L. L., \& Tesser, A. (1989). Toward a motivational and structural theory of ruminative thought. In J. S. Uleman \& J. A. Bargh (Eds.), Unintended thought (pp. 306-326). New York: Guilford Press.

Murray, E. J., \& Segal, D. L. (1994). Emotional processing in vocal and written expression of feelings about traumatic experiences. Journal of Traumatic Stress, 7, 391-405. 
Nolen-Hoeksema, S. (2003). Women who think too much: How to break free of overthinking and reclaim your life. New York: Henry Holt.

Nolen-Hoeksema, S., McBride, A., \& Larson, J. (1997). Rumination and psychological distress among bereaved partners. Journal of Personality and Social Psychology, 72, 855-862.

Nolen-Hoeksema, S., \& Morrow, J. (1991). A prospective study of depression and posttraumatic stress symptoms after a natural disaster: The 1989 Loma Prieta earthquake. Journal of Personality and Social Psychology, 61, 115-121.

Pennebaker, J. W. (1993). Social mechanisms of constraint. In D. M. Wegner \& J. W. Pennebaker (Eds.), Handbook of mental control (pp. 200-219). Englewood Cliffs, NJ: Prentice Hall.

Pennebaker, J. W., \& Francis, M. E. (1996). Cognitive, emotional, and language processes in disclosure. Cognition \& Emotion, 10, 601-626.

Pennebaker, J. W., \& Graybeal, A. (2001). Patterns of natural language use: Disclosure, personality, and social integration. Current Directions in Psychological Science, 10, 90-93.

Pennebaker, J. W., Mayne, T. J., \& Francis, M. E. (1997). Linguistic predictors of adaptive bereavement. Journal of Personality and Social Psychology, 72, 863-871.

Pennebaker, J. W., \& Seagal, J. (1999). Forming a story: The health benefits of narrative. Journal of Clinical Psychology, 55, 1243-1254.

Ryff, C. D. (1989). Happiness is everything, or is it? Explorations on the meaning of psychological well-being. Journal of Personality and Social Psychology, 57, 1069-1081.

Salovey, P., Rothman, A. J., Detweiler, J. B., \& Steward, W. T. (2000). Emotional states and physical health. American Psychologist, 55, 110121.

Segerstrom, S. C., Stanton, A. L., Alden, L. E., \& Shortridge, B. E. (2003). A multidimensional structure for repetitive thought: What's on your mind, and how, and how much? Journal of Personality and Social Psychology, 85, 909-921.

Seligman, M. E. P., \& Csikszentmihalyi, M. (2000). Positive psychology: An introduction. American Psychologist, 55, 5-14.

Sherbourne, C. D., Allen, H. M., Kamberg, C. J., \& Wells, K. B. (1992). Physical psychophysiologic symptoms measure. In A. L. Stewart \& J. E. Ware (Eds.), Measuring functioning and well-being (pp. 260-272). Durham, NC: Duke University Press.

Singer, J. A. (2004). Narrative identity and meaning making across the adult lifespan: An introduction. Journal of Personality, 72, 437-459.

Smyth, J. M. (1998). Written emotional expression: Effect sizes, outcome types, and moderating variables. Journal of Consulting and Clinical Psychology, 66, 174-184.

Smyth, J. M., True, N., \& Souto, J. (2001). Effects of writing about traumatic experiences: The necessity for narrative structuring. Journal of Social and Clinical Psychology, 20, 161-172.

Stanton, A. L., Kirk, S. B., Cameron, C. L., \& Danoff-Burg, S. (2000). Coping through emotional approach: Scale construction and validation. Journal of Personality and Social Psychology, 78, 1150-1169.

Stewart, A. L., Hays, R. D., \& Ware, J. E. (1988). The MOS short-form general health survey: Reliability and validity in a patient population. Medical Care, 26, 724-735.

Stone, A. A., Cox, D. S., Valdimarsdottir, H., Jandorf, L., \& Neale, J. M. (1987). Evidence that secretory IgA antibody is associated with daily mood. Journal of Personality and Social Psychology, 52, 988-993.

Swinkels, A., \& Giuliano, T. A. (1995). The measurement and conceptualization of mood awareness: Monitoring and labeling one's mood states. Personality and Social Psychology Bulletin, 21, 934-949.

Tkach, C. (2005). Unlocking the treasury of human kindness: Enduring improvements in mood, happiness, and self-evaluations. Unpublished doctoral dissertation, Department of Psychology, University of California, Riverside.

Trapnell, P. D., \& Campbell, J. D. (1999). Private self-consciousness and the five-factor model of personality: Distinguishing rumination from reflection. Journal of Personality and Social Psychology, 76, 284-304.

van der Kolk, B., \& van der Hart, O. (1991). The intrusive past: The flexibility of memory and the engraving of trauma. American Imago, 48 , $424-454$.

Vinokur, A., Schul, Y., \& Caplan, R. D. (1987). Determinants of perceived social support: Interpersonal transactions, personal outlook, and transient affective states. Journal of Personality and Social Psychology, 53, $1137-1145$

Watson, D., Clark, L. A., \& Tellegen, A. (1988). Development and validation of brief measures of positive and negative affect: The PANAS scales. Journal of Personality and Social Psychology, 54, 1063-1070.

Wilson, T. D., Centerbar, D. B., Kermer, D. A., \& Gilbert, D. T. (2005). The pleasures of uncertainty: Prolonging positive moods in ways people do not anticipate. Journal of Personality and Social Psychology, 88, $5-21$.

Wilson, T. D., \& Gilbert, D. T. (2003). Affective forecasting. Advances in Experimental Social Psychology, 35, 345-411.

Wood, J. V., Heimpel, S. A., \& Michela, J. L. (2003). Savoring versus dampening: Self-esteem differences in regulating positive affect. Journal of Personality and Social Psychology, 85, 566-580.

Received August 8, 2003

Revision received November 2, 2005

Accepted November 4, 2005

\section{E-Mail Notification of Your Latest Issue Online!}

Would you like to know when the next issue of your favorite APA journal will be available online? This service is now available to you. Sign up at http://watson.apa.org/ notify/ and you will be notified by e-mail when issues of interest to you become available! 